\title{
ON ONCE AND FUTURE THINGS: A TEMPORAL ASYMMETRY IN JUDGMENTS OF LIKELIHOOD
}

\author{
A Dissertation \\ Presented to the Faculty of the Graduate School \\ of Cornell University \\ In Partial Fulfillment of the Requirements for the Degree of \\ Doctor of Philosophy
}

by

Karlene Cheryl Hanko

January 2008 
(C) 2008 Karlene Cheryl Hanko 


\title{
ON ONCE AND FUTURE THINGS: A TEMPORAL ASYMMETRY IN JUDGMENTS OF LIKELIHOOD
}

\author{
Karlene Cheryl Hanko, Ph.D. \\ Cornell University 2008
}

What do people see when they gaze into the future? Many people, at least among those in Western cultures, see a future brimming with possibilities. The past, on the other hand, is rarely described as being full of possibility. This is not surprising, as the future is associated with a greater number of possible outcomes, is unknown, and is potentially changeable, whereas the past is associated with fewer possible outcomes, is known or potentially knowable, and cannot be changed. In this dissertation, I argue that because people associate the future with openness and possibility more so than the past, they tend to see any particular uncertain event as more probable in the future than in the past, all else being equal. That is, people judge focal future events to be more likely than otherwise identical past events, once differences in knowledge of the past and future are eliminated. I report a series of studies aimed at documenting this phenomenon and testing the proposed mechanism, the tendency to associate the future with openness and possibility. In Chapter Two, I describe three studies demonstrating this past-future asymmetry in likelihood judgments and testing some of the parameters of this phenomenon. In Chapter Three, I report the results of three studies that provide support for the hypothesized cause of this effect, the association between the future and possibility. In Chapter Four, I describe two 
studies examining some extensions of this effect beyond the realm of likelihood judgments. Finally, in Chapter Five I discuss some implications and boundary conditions of this effect, and outline future directions for this work. 


\section{BIOGRAPHICAL SKETCH}

Karlene Hanko received her B.A. in Psychology from the University of Pennsylvania, where she worked with Paul Rozin and John Sabini, in May 2002. Wishing to avoid the "real world" for as long as possible, she promptly moved to Ithaca, New York and enrolled in graduate school at Cornell University. She began working on her Ph.D. in Social and Personality Psychology in August 2002 under the guidance of Thomas Gilovich. Upon completing her Ph.D., Karlene will travel to Germany to take a two-year appointment as a Postdoctoral Fellow at the University of Cologne. 
For my parents, Gayle and Paul 


\section{ACKNOWLEDGMENTS}

I could not have written this dissertation without the invaluable guidance and assistance of my advisor, Thomas Gilovich. Tom's creativity and ability to find interesting solutions to difficult problems is something I will continue to admire and aspire to in my final days at Cornell and beyond. I also wish to thank the other members of my committee, David Dunning, Melissa Ferguson and David Field for their helpful advice on this and many other projects. I am also grateful to the other graduate students in the Social and Personality Psychology area for their feedback throughout the course of this project, and especially to Jane Risen, who is not only a wonderful friend but also an inspiration in my own research career. Finally, I would like to thank Paul Stillman, Kim Monty, Kate Ernstrom, Tsipora Nemes, Al Herrara, and the many other undergraduate research assistants who have spent countless hours running the studies in this dissertation. 


\section{TABLE OF CONTENTS}

BIOGRAPHICAL SKETCH

DEDICATION iv

ACKNOWLEDGMENTS V V

TABLE OF CONTENTS vi

LIST OF FIGURES vii

LIST OF TABLES viii

CHAPTER ONE: INTRODUCTION 1

CHAPTER TWO: WHEN THE FUTURE IS MORE 10

LIKELY THAN THE PAST

CHAPTER THREE: INTO THE GREAT WIDE OPEN 28

CHAPTER FOUR: BEYOND LIKELIHOOD 47

CHAPTER FIVE: GENERAL DISCUSSION 59

$\begin{array}{ll}\text { APPENDIX } & 75\end{array}$

$\begin{array}{ll}\text { REFERENCES } & 79\end{array}$ 


\section{LIST OF FIGURES}

Figure 3.1. Mean likelihood judgment as a function of the timing of the events and article manipulation.

Figure 4.1. Mean estimates of the percentage of Cornell

students who would agree with each statement, by timing condition.

Figure 4.2. Timeline that participants were asked to decorate with color in Study $8 b$. 


\section{LIST OF TABLES}

Table 2.1. Mean likelihood ratings for events in Study 1, by temporal perspective.

Table 2.2. Mean likelihood ratings by temporal

perspective, and mean positivity ratings for each event in Study 3.

Table 3.1. Mean ratings of past and future along six dimensions.

Table 3.2. Design of the Past-Future IAT. 


\section{CHAPTER ONE:}

\section{INTRODUCTION}

What do people see when they gaze into the future? Many people, at least among those in Western cultures, see a future brimming with possibilities. This tendency to see the future as full of possibility is reflected in everyday language, as when people say that the "future is wide open" or tell their children "you can be anything you want to be." This tendency is also reflected in the popular culture, as when science fiction novels and films feature fantastic visions of the future that are rarely realized when the depicted era actually arrives.

The past, on the other hand, is rarely described as being full of possibility. This is not surprising, as the past is fixed in a way that the future is not. Multiple possibilities exist for the outcome of any uncertain future event, whereas only one outcome exists for any given past event. The future is not yet known, whereas in many cases the past is known or, at least, potentially knowable. The future may yet be shaped by human actions (at least according to some philosophical positions), whereas the past cannot be changed. For all of these reasons, we can describe the future as more "open" than the past.

What are the implications of this difference in the openness of the past and future for the way in which people think about uncertain past and future events? I propose that because people see more possibility in the future than in the past, they tend to see any particular uncertain event as more possible - and hence more probable - in the future than in the past. In certain cases such a tendency is perfectly rational. I know I have never won the lottery before, for example, so the chances I will win the lottery 
in the future - even if miniscule - are necessarily greater than the chances that I have won the lottery in the past. In cases where the past is just as uncertain as the future, however, the timing of an event should not influence perceptions of its likelihood. Until I check the winning numbers, the chances that my lottery ticket will be worth millions are the same five minutes before the drawing as they are five minutes afterward. But because I associate the future with openness and possibility more so than the past, I may judge my chances of winning to be higher before the winning numbers are drawn than after they are drawn, even though it is irrational to do so.

In what follows I will present a series of studies aimed at testing this hypothesis, that people judge uncertain future events to be more likely than equivalent past events even when differences in knowledge of the past and future are eliminated. After documenting this timing effect in likelihood judgments, I will test the proposed mechanism: the tendency to associate the future with openness and possibility more so than the past. Finally, I will explore some extensions of this phenomenon beyond the realm of likelihood judgments.

\section{The Open Future}

As noted above, there are many ways in which we can consider the future to be more open than the past. The future is associated with a greater number of possibilities, is unknown, and is potentially changeable, whereas the past is associated with fewer possibilities, is known or potentially knowable, and cannot be changed. The knowledge that the future is more open than the past may lead people to treat past and future events quite differently. Indeed, previous research has documented a 
number of differences in the way people describe, explain, and understand past and future events. For example, Bavelas (1973) asked participants to create an itinerary for a fictional vacation, said to take place in either the following year or the previous year. Although participants listed more vacation spots when imagining a past vacation, they generated more unique ideas when imaging a future vacation. Similar results were obtained by Watzke and Webb (cited in Weick, 1979). They conducted a study several days before the 1970 Super Bowl in which participants were asked to imagine it was either the day before or the day after the game, and to describe how the game would/did unfold. Participants imagining that the game would happen tomorrow wrote more variable and more creative accounts of what would happen in the game than did those imagining that the game happened yesterday. Even though participants had no more knowledge of the past than of the future in these studies, they imagined that the future would be more unique and unusual than the past.

In addition to approaching the future with a more creative mindset, people appear to give more weight to temporary or transient factors relative to stable ones when predicting future events than when "postdicting" past events. Sanna and Swim (1992) asked participants to imagine a past or future academic experience (either "acing" or failing a test) and then to judge the causes of their imagined behavior. Participants were more likely to attribute their behavior to stable causes (both internal and external to themselves) when imaging past behavior than when imagining future behavior. Similarly, Grant and Tybout (2007) found that participants asked to predict the success of a future marketing campaign were more likely to take into account temporary factors associated with 
the product launch (i.e., current market conditions) than were those asked to postdict the success of a past marketing campaign. The results of these studies suggest that, in comparison to uncertain past events, people see uncertain future events as less fixed, as more malleable and open to change.

This tendency to see the future as full of unique possibilities is not limited to adults. Even young children seem to imbue the future with more possibility than the past. In one experiment (Robinson, Rowley, Beck, Carroll \& Apperly, 2006), children set out mats to catch a block that would fall to the ground after being pushed through one of several elevated doors. The children were more likely to set out multiple mats (one under each door from which the block might emerge) if the experimenter had yet to place the block behind a door than if the block had already been positioned behind one of the doors. In this latter case, the children tended to set out just one mat, as though they had difficulty recognizing that there was more than one place the block could be. These results suggest that young children find it easier to acknowledge multiple possibilities when they are dealing with uncertain future events than when they are dealing with uncertain past events. Indeed, the ability to acknowledge competing possibilities for uncertain past events does not seem to emerge until the age of 7 or 8 (Robinson et al., 2006).

The tendency to associate the future with openness and possibility may help to explain why many sports fans are averse to watching prerecorded sports events that they would happily watch live. According to Vosgerau, Wertenbroch and Carmon (2006), live matches are more exciting to watch than pre-recorded ones precisely because they are as-of- 
yet unresolved. Even if the outcome of a match is unknown to the sports fan, they argue, the fact that the match has already occurred makes it seem more determined and hence less exciting to watch. Although Vosgerau et al. do not state this explicitly, their account seems to imply that determined events are less exciting because it seems less likely that something terribly thrilling and unexpected will happen. A tendency to endow the future with more potential than the past may also help to explain why people tend to underweight past experiences when predicting similar future ones. For example, people routinely underestimate how long it will take them to complete a variety of tasks despite a wealth of past experience suggesting such tasks are likely to take longer than they think (Buehler, Griffin \& Ross, 1994). This planning fallacy is understandable, however, if people assume that the future will afford them opportunities that the past did not. The fact that I did not manage to write a paper, clean my entire apartment, and finish my grading last weekend, for example, doesn't mean it isn't possible to get all of these tasks done next weekend.

The Likely Future

An asymmetry in the openness of the past and future may also have implications for the way in which people judge the likelihood of past and future events. If the future is more open than the past, people may be likely to judge any particular event to be more possible - and hence more probable - in the future than in the past, all other things being equal. That is, controlling for differences in knowledge of the past versus the future, people may see uncertain future events to be more likely than equivalent 
past events because they associate the future with possibility more so than the past.

Is there any evidence to support this claim? Although some studies have examined beliefs about the likelihood of past versus future events, these investigations have typically focused on events for which there is an asymmetry in knowledge of the past versus the future. For example, research on the hindsight bias has found that, after learning the outcome of a past event, people tend to believe they "knew it all along" - to see that particular outcome as more likely in retrospect than they would have in prospect (Fischhoff, 1975). Given that the aim of this research program is to examine the biasing influence of outcome information, these studies necessarily create an imbalance in information, comparing people's beliefs about the likelihood of some outcome before versus after learning the true outcome. Thus, these studies cannot shed light on the question of whether people will see future events as more probable than equivalent past events when information about the past and future is held constant.

Only a handful of investigations have compared beliefs about past versus future events when differences in knowledge of the past versus the future are eliminated. Although limited in number, the results of these studies suggest that people do see at least certain kinds of focal outcomes as more likely in the future than in the past. Rothbart and Snyder (1970), for example, found that participants betting on the outcome of a die roll expressed more confidence in their bets, and were willing to wager more money on them, if they were allowed to predict the outcome of the roll in advance than if they were asked to "postdict" the outcome after the die had been rolled (but before they were allowed to see the outcome). 
Similarly, Strickland, Lewicki and Katz (1966) found that participants chose riskier bets - that is, bets with lower odds of winning but higher payoffs - when betting on a die before it was rolled than when betting after the die was rolled.

Rothbart and Snyder (1970) interpreted their results as evidence of magical thinking in situations that encourage illusory perceptions of control. The idea is that people believe, however implicitly, that they can influence the outcome of a future die roll more so than the outcome of a past die roll, and thus they are more confident about their chances of winning in the former case than in the latter. Also consistent with this argument is the finding that individuals are more likely to cooperate in a prisoner's dilemma game if they choose their move before their partner chooses his or hers than if they move after their partner has made a choice (Morris, Sim \& Girotto, 1998).

Some authors have rejected this magical thinking interpretation, however. Brun and Teigen (1990) argued that people are more confident in prediction than in postdiction because of an asymmetry in the extent to which one's internal uncertainty is mirrored by external uncertainty. In the case of prediction, it is perfectly reasonable to be uncertain as the future outcome is not yet knowable. In the case of postdiction, however, there is an imbalance between what the individual knows and what is in fact knowable. This imbalance is aversive, and thus people feel more comfortable predicting the outcome of events in advance, and feel more confident in their predictions when they do so (see Fox \& Tversky, 1995, for a similar argument regarding ambiguity aversion). 
Another possibility, however, is that people simply associate the future with openness and possibility more so than the past, and thus they tend to see any focal uncertain event (not just those for which people harbor illusions of control) as more probable in the future than in the past. When Rothbart and Snyder (1970) asked their participants how confident they were in their guesses, participants likely attempted to estimate the probability of the die coming up the way they called it. If there is a tendency for people to see such possibilities as more likely in the future (i.e., in prediction) than in the past (i.e., in postdiction), this would account for the differences in participants' reported confidence and the size of the bets they were willing to place. This would also account for Brun and Teigen's (1990) finding that when given the choice, people prefer prediction over postdiction, as they may feel more confident when predicting future outcomes than when postdicting past ones. In addition to explaining previous research findings, this account predicts that we should see an asymmetry in likelihood estimates when people are asked to predict a wide range of past and future outcomes even when people have no control (either real or illusory) over the events in question.

But why should seeing the future as more open than the past lead to higher likelihood estimates for future events? After all, if all things are more possible in the future than in the past, shouldn't this entail that any particular thing is less possible in the future than in the past? I believe the key to resolving this apparent contradiction lies in the welldocumented tendency for people to focus on a small subset of the available information when making predictions, testing hypotheses, and evaluating evidence (Klayman \& Ha, 1987; Snyder \& Swann, 1978; 
Wilson, Wheatley, Meyers, Gilbert \& Axsom, 2000). This focalism means that when people are considering the likelihood of an event's occurrence, either in the future or in the past, they are unlikely to spend much time thinking about other events that may prevent, crowd out, or otherwise interfere with the focal event. Instead, they may only briefly review the evidence directly related to the occurrence of the focal event. Because they fail to consider competing events or outcomes, then, people may tend to judge only the focal event as more likely in the future than in the past.

In this dissertation I report a series of studies aimed to test the hypothesis that because people associate the future (but not the past) with openness and possibility, they tend to see uncertain future events as more likely than identical past events, all else being equal. In Chapter Two, I describe three studies that document this past-future asymmetry in likelihood judgments and test some of the parameters of this phenomenon. In Chapter Three, I report the results of three studies that provide support for the hypothesized cause of this effect, the association between the future and possibility. In Chapter Four, I describe two studies examining some extensions of this effect beyond the realm of likelihood judgments. Finally, in Chapter Five I discuss some implications and boundary conditions of this effect, and outline future directions for this work. 
CHAPTER TWO:

\section{WHEN THE FUTURE IS MORE LIKELY THAN THE PAST}

In this chapter I report the results of three studies that examined whether people judge uncertain future events to be more likely than identical past events, all other things being equal. In each study, participants judged the likelihood that one or more focal events would occur in the future or did occur in the past. I took care to ask about events that, normatively speaking, were no more likely to happen at one time than another. Thus, I avoided topics that are subject to historical trends as well as those for which participants might have knowledge (either real or inferred) of past events. ${ }^{1}$ This allowed me to focus on the effect of merely describing something as a past or future event on people's beliefs about that event.

In Study 1, I asked participants to estimate the likelihood that a target person would experience, or would have experienced, a variety of events over the course of a given one-week period. Some participants provided these estimates for a week in the near future whereas others did so for a week in the recent past. I predicted that participants would tend to see the events as more likely if they were asked about a future week than if they were asked about a past week. In Study 2, I replicated the results of Study 1 in another context (judging the likelihood of a mentally ill individual attempting suicide) and examined whether this effect is

\footnotetext{
${ }^{1}$ By real knowledge, I mean that an individual possesses some knowledge indicating that an event either did or did not occur in the past. By inferred knowledge, I mean that an individual possesses the belief that had this event occurred, he would have heard about it, and thus he can infer from his ignorance that the event did not in fact occur.
} 
moderated by the overall frequency of the event in question - that is, whether it is rare or common in general. In Study 3, I asked participants to judge the likelihood that they themselves had experienced certain events in the past and the likelihood that they would experience those same events in the future. Because people often know that they have experienced a particular event at some point in the past, but are less likely to know whether they experienced that event on a specific date in the past, I asked participants to judge the likelihood that they had experienced the events in question on a specific date in the distant past. This procedure minimized the possibility that participants would have greater knowledge of the past than of the future, and allowed me to focus solely on the question of whether people see a variety of events as more likely to happen to them in the future than to have happened to them in the past.

Study 1: Everyday Events

\section{Method}

Seventy-seven participants (46 female, ages 18 to 39 , with a median age of 20) were recruited at public locations on the Cornell campus and asked to complete several short questionnaires in exchange for a candy bar. The current study always appeared first in the set of questionnaires.

Participants read a short description of a target person named Jen and then rated the likelihood of Jen experiencing each of 12 everyday events over the course of a particular week. Two versions of the questionnaire were created, and were randomly distributed to participants. Half rated the likelihood that Jen would experience each of the events sometime during the following week, whereas the other half rated the 
likelihood that she had experienced those same events sometime during the prior week. Thus, the two versions of the questionnaire were identical except that one asked for judgments about future events whereas the other asked for judgments about past events.

The description of Jen, which was meant to give participants some basis for their judgments without providing information that would make any particular event seem certain to happen or certain not to happen, was as follows:

Jen is a typical Cornell undergraduate. She is a junior, majoring in Economics and minoring in French. She is originally from the West Coast, and although she misses the California sunshine, she would like to move to New York City after graduation. Jen can often be found studying in Olin library, a vanilla latte from the café in hand. In her spare time, Jen likes to watch movies at the Cornell cinema and hang out with her roommates.

After reading this description, participants judged the likelihood of Jen experiencing each of the 12 events during the specified time period. Care was taken to select events that would be equally likely to occur regardless of the time period in question (see Table 2.1, below, for the list of events). ${ }^{2}$ Ratings were made on 7-point scales anchored at 1 ("extremely unlikely”) and 7 (“extremely likely”).

\footnotetext{
${ }^{2}$ Despite my best intentions, one item I selected was in fact tied to external circumstances that differed depending on the time period in question. The data for this study were collected at the beginning of a particularly rainy week in October that came on the heels of a rather sunny week. Thus, participants had an a priori reason to find it less likely that Jen would go on a hike in the upcoming week than that she had gone on a hike in the previous week. Because the direction of this reasoning runs contrary to my hypothesis, however, removing this item would only strengthen the results.
} 
Results and Discussion

Because mean judgments differed substantially depending on the event in question, ratings for each event were normalized and the resulting z-scores were averaged to form a composite measure of likelihood. This composite was subjected to a 2 (timing: past vs. future) x 2 (gender) analysis of variance (ANOVA). This analysis revealed only a main effect of timing, $F(1,73)=4.59, p<.05$. Overall, participants believed it more likely that the events would occur over the following week $(M=.11, S D=$ $.43)$ than that they had occurred over the prior week $(M=-.10, S D=.38)$. This pattern of higher likelihood estimates for future than for past events occurred for 10 of the 12 individual items, a significant result according to the sign test, $p<.05$. The individual means are displayed in Table 2.1.

To explore whether these findings apply equally to positive and negative events, I asked a separate sample of 30 participants to rate the valence of each of the 12 events on 7-point scales anchored at 1 ("extremely negative") and 7 ("extremely positive"). Then, for each item, I computed the mean difference between the likelihood ratings given by participants in each of the two conditions, and regressed this difference onto the mean positivity of that item. This analysis showed no relationship between the size of the past-future effect and the valence of the item, $\beta=-.001, r=-.003, t(10)<1, n s$. Thus, it appears that the tendency to judge uncertain outcomes as more likely in the future than in the past applies equally to positive and negative events, and is not due to greater optimism (i.e., believing only that positive events are more likely) when predicting the future. 
Table 2.1

Mean likelihood ratings for events in Study 1, by temporal perspective

\begin{tabular}{lccc}
\hline \multicolumn{1}{c}{ Item } & Future & Past & Difference \\
\hline Argue with a friend & 4.21 & 3.97 & 0.24 \\
Arrive late to class & 4.32 & 3.87 & 0.45 \\
Begin a diet & 3.89 & 3.10 & 0.79 \\
Begin a romantic relationship & 3.71 & 2.79 & 0.92 \\
Call parents & 5.41 & 5.18 & 0.23 \\
Do laundry & 5.32 & 4.90 & 0.42 \\
Feel sad & 5.03 & 4.90 & 0.13 \\
Go on a hike & 2.21 & 2.54 & -0.33 \\
Go to a party & 5.29 & 4.85 & 0.54 \\
Go to the gym & 4.54 & 4.13 & 0.41 \\
Go to office hours & 4.95 & 5.05 & -0.10 \\
Treat a friend to dinner & 3.76 & 3.79 & -0.03 \\
\hline Average & 4.38 & 4.09 & 0.29 \\
\hline
\end{tabular}

Study 2: Base Rates

The results of Study 1 support the hypothesis that people see uncertain future events as more likely than identical past events, all other things being equal. In a second study, I aimed to replicate Study 1 in a different context, and to examine whether this effect is moderated by the frequency of the events in question. I hypothesize that because people associate the future with openness and possibility, they will tend to see focal uncertain events as more likely in the future than in the past. Another possibility, however, is that people prefer not to think very 
carefully about the future before it arrives, and thus they tend to hold overly-simplified visions of the future. This account predicts that likely events will be seen as more likely in the future, but that unlikely events will be seen as even less likely. Although I asked about a variety of events in Study 1, all of the events were ones that were fairly common in undergraduate life. As Study 1 alone cannot rule out this alternative account, in Study 2 I varied the prior base rate of the event in order to examine whether thinking about the future elevates probability estimates, or simply makes them more extreme.

\section{Method}

Participants were 80 Cornell undergraduates who volunteered to complete a brief questionnaire in the Social Psychology laboratory while waiting to be called in for another experiment. The study employed a 2 (base rate: high vs. low) x 2 (timing: past vs. future) between-subjects design. Participants read that a particular psychiatric disorder was associated with either a relatively high or a relatively low risk of suicide. Participants in the High Base Rate condition were told that 80 percent of patients with this disorder attempt suicide within five years of their release from inpatient care, whereas those in the Low Base Rate condition were told that this number was 20 percent. Participants then read a brief description of "Mr. S.," a 26-year old man said to suffer from this psychiatric disorder. As in Study 1, the description was intended to give participants some basis for their judgments without biasing them toward believing suicide was especially likely or especially unlikely. The description was as follows: 
Mr. S. is a 26 year-old man who suffers from this psychiatric disorder. Diagnosed at the age of 21, Mr. S. spent about four years in outpatient therapy, but was hospitalized at the age of 25 after suffering an acute mental breakdown. Mr. S. spent nine months in the hospital, where he received a combination of drug, group, and one-on-one therapies. Upon his release from the hospital, his doctor wrote the following in his case file: "Mr. S.'s condition has greatly improved in the last nine months. Although he occasionally experiences severe mood swings, he is generally stable and has made significant advances in his journey towards self-acceptance."

Participants were then asked to judge the likelihood of Mr. S. attempting suicide within a specific five-year period on a 9-point scale anchored at 1 ("not at all likely") and 9 ("highly likely"). Half were asked imagine that it was the day of Mr. S's release from the hospital, and to predict the likelihood that he would attempt suicide sometime in the next five years. The other half were asked to imagine that it was five years after Mr. S's release, and to postdict the likelihood that he had attempted suicide sometime in the past five years.

Results and Discussion

A 2 (timing: past vs. future) x 2 (base rate: high vs. low) ANOVA on likelihood ratings revealed a main effect of base rate, $F(1,76)=18.21$, $p<.0005$. Not surprisingly, participants rated Mr. S.'s chances of attempting suicide to be higher when the base rate of this behavior was high $(M=6.2, S D=1.9)$ than when it was low $(M=4.4, S D=1.8)$. More important, this analysis also revealed a significant main effect of timing, 
$F(1,76)=4.36, p<.05$. Participants rated his likelihood of attempting suicide to be higher when they were predicting his future behavior $(M=$ $5.8, S D=1.8)$ than when they were postdicting his past behavior $(M=$ $4.9, S D=2.2$ ). There was no hint of an interaction between timing and base rate, $F(1,76)<1$, suggesting that the effect of temporal perspective did not depend on the prior base rate of the event in question. Participants believed a future suicide attempt was more likely than a past attempt regardless of whether suicide attempts in general were common or rare among individuals with this disorder. These results support the hypothesis that people generally judge uncertain future events to be more likely than identical past events, and do not support the alternative possibility that people simply see the future in more deterministic terms than the past.

One may ask what these findings mean for formal models of probabilistic reasoning such as Bayes' rule. Bayes' rule is a normative model that explains how to calculate the probability of an event when information is uncertain, and is often used to revise the degree of support for a hypothesis in light of new information. Although research suggests that people often fail to reason according to Bayesian principles in everyday judgment and decision making (Kahneman \& Tversky, 1973), legal and medical practitioners are routinely trained to use Bayes' rule to estimate the probability of some outcome, such as the death of a patient or the guilt of a defendant, based on the available evidence. If people judge the likelihood of uncertain future events to be higher than that of comparable past events, how might this affect the use of Bayes' rule? 
One way to answer this question is to examine how Bayes' rule would apply to the judgment participants made in Study 2. According to Bayes' rule, the probability of Mr. S. attempting suicide given the personality sketch provided by his doctor is defined by the following equation:

$$
\mathrm{P}(\text { suicide } \mid \text { sketch })=\frac{\mathrm{P}(\text { sketch } \mid \text { suicide }) * \mathrm{P}(\text { suicide })}{\mathrm{P}(\text { sketch })}
$$

where

$\mathrm{P}($ sketch I suicide $)=$ the probability of a person having this particular personality sketch given that he or she attempts suicide $\mathrm{P}($ suicide $)=$ the probability of an individual attempting suicide in general $\mathrm{P}($ sketch $)=\mathrm{P}($ sketch I suicide $) * \mathrm{P}($ suicide $)+\mathrm{P}($ sketch I no suicide $) *$ $\mathrm{P}$ (no suicide), or the probability of an individual having this particular personality sketch in general (summed across those who attempt suicide and those who do not).

The question, then, is where in the above equation might the timing of the judgment exert an influence? $\mathrm{P}$ (suicide), the prior probability of a suicide attempt, is fixed by the scenario (as either .20 or .80) and seems unlikely to be influenced by the timing of the judgment. On the other hand, $\mathrm{P}$ (sketch I suicide), the probability of an individual having this particular personality sketch given a suicide attempt, might be influenced by the timing of the judgment. In particular, participants judging the likelihood of a future suicide attempt might interpret this parameter as the likelihood of having this particular personality sketch given that one is 
going to attempt suicide, whereas those judging the likelihood of a past suicide attempt might interpret it as the likelihood of having this personality sketch given that one has attempted suicide. This would lead to different estimates both for $\mathrm{P}($ sketch I suicide) and for $\mathrm{P}$ (sketch), which relies on $\mathrm{P}$ (sketch I suicide), and ultimately to different estimates for $\mathrm{P}$ (suicide I sketch) depending on the time period in question.

The above analysis suggests that even if practitioners use Bayes' rule appropriately, the timing of the event in question may bias some of the parameter estimates used in calculating the probability of interest. For example, a doctor estimating the probability that a patient has recently developed a particular disease may come to a different conclusion than a doctor estimating the probability that that same patient will soon develop the disease, even if they are basing their estimates on the very same test result. This could have important consequences for how these doctors approach the issue of treatment, and thus for the patient's ultimate health and survival. These conclusions are speculative, as I did not ask participants in Study 2 for their estimates of $\mathrm{P}$ (sketch I suicide), but they do suggest that a closer look into how individuals use Bayes' rule when calculating the likelihood of past and future events should be a goal of future research.

Study 3: Predicting vs. Postdicting the Self

In the studies reported thus far, I asked participants to make judgments about the likelihood of other people experiencing positive or negative outcomes, and found that participants believe both positive and negative events are more likely in the future than in the past. One might ask whether these same findings would hold if people were making 
judgments about their own chances of experiencing positive and negative outcomes. A number of researchers have found that people see their own futures in positive terms, believing, for example, that they are more likely than their peers to experience positive events and less likely than their peers to experience negative events over the course of their lives (Weinstein, 1980). If people are motivated to believe they have bright and healthy futures, then, the tendency to see future events as more likely than past events may hold only for positive and neutral self-relevant events, and may be nonexistent (or even reversed) for negative selfrelevant events.

To test this hypothesis, I asked participants in a third study to make judgments about the likelihood of experiencing a variety of events in their own lives. Unlike the first two studies, Study 3 used a within-subjects design, in which all participants judged both past and future events. In order to minimize differences in participants' knowledge of their own pasts versus futures, I asked participants to judge the likelihood of experiencing these events on a specific date in the past or future. Because participants are unlikely to know exactly what happened to them on a random day in the past, I was able to examine the effect of simply situating an event in the past or future on participants' beliefs about the likelihood of that event.

\section{Method}

Thirty-nine Cornell undergraduates participated in the present study, which took the form of a two-page questionnaire distributed in a packet of unrelated surveys being collected by various researchers in the Social Psychology laboratory. On one page of the questionnaire, 
participants were asked to judge the likelihood that they would engage in a variety of behaviors on a particular day in the future; on the other page, they were asked to judge the likelihood that they had engaged in those same behaviors on a particular day in the past. More specifically, the instructions on the Future page read:

Few people know exactly what they will be doing on a particular day in the distant future. But we are interested in your beliefs about what you are likely to do on a particular day in the future. In this case, we are interested in what you believe you will do exactly one year from today, on this date in 2008 . Thus, please rate the likelihood that you will engage in each of the following behaviors on this date exactly one year from now by circling a number on the scale next to each behavior. Please limit your reports to your beliefs about what you are likely to do over the course of that one day.

Participants then encountered a list of 12 events, and rated the likelihood that they would experience each of those events on the specified date using a 7-point scale anchored at 1 ("extremely unlikely") and 7 ("extremely likely") (see Table 2.2, below, for the list of events). The instructions for the Past page were almost identical to those for the Future page, except that participants were asked to judge the likelihood that they had experienced those same events "exactly one year ago, on this date in 2006." The order of the two pages was counterbalanced across participants such that some participants made judgments about the future first, whereas others made judgments about the past first. 
Results and Discussion

To examine the effect of timing across items, I created two composites: the Future composite, which was the mean of participants' 12 likelihood estimates for the future day, and the Past composite, which was the mean of participants' 12 likelihood estimates for the past day. A mixed-model ANOVA with timing (past vs. future) as a within-subjects variable and order (future first vs. past first) as a between-subjects variable revealed the predicted main effect of timing, $F(1,37)=8.91, p<$ .005 . Overall, participants believed they would be more likely to experience the 12 events one year into the future than that they had experienced those same events one year into the past $(M \mathrm{~s}=3.86$ and 3.60, respectively). The means for each item are displayed in Table 2.2.

As in Study 1, I asked a separate sample of participants $(n=13)$ to rate the valence of each of the 12 events on 7-point scales anchored at 1 ("extremely negative") and 7 ("extremely positive"), in order to examine whether the timing effect is moderated by the valence of the events. For each event, I computed the mean difference between the past and future likelihood ratings given by participants, and regressed this difference onto the mean positivity of that item. This analysis revealed a significant positive relationship between the size of the past-future difference and the valence of the item, $\beta=.278, r=.68, t(10)=2.92, p<.05$. The more

\footnotetext{
${ }^{3}$ This analysis also revealed a marginally significant tendency for participants to provide higher likelihood judgments overall when they made judgments about the future first than when they made judgments about the past first, $M \mathrm{~s}=3.91$ and 3.57, respectively, $F(1,37)=3.92, p<.06$. This finding is understandable if participants' first set of likelihood estimates served as an anchor for their second set of estimates. Because participants provided higher likelihood estimates for future events than for past events, those who judged future events first started with a higher anchor than those who judged past events first.
} 
positive an event was, the more likely participants were to see it as more probable in the future than in the past.

Table 2.2

Mean likelihood ratings by temporal perspective, and mean positivity ratings for each event in Study 3

\begin{tabular}{lcccc}
\hline \multirow{2}{*}{ Event } & & \multicolumn{3}{c}{ Likelihood } \\
\cline { 3 - 5 } & Positivity & Future & Past & Difference \\
\hline Eat cereal for breakfast & 5.31 & 3.44 & 3.00 & 0.44 \\
Wear something red & 4.15 & 3.69 & 2.97 & 0.72 \\
Have a phone conversation $>30$ mins. & 4.67 & 4.54 & 3.90 & 0.64 \\
Cook dinner & 5.00 & 3.33 & 2.03 & 1.31 \\
Feel lonely & 1.77 & 3.31 & 3.82 & -0.51 \\
Exercise or play a sport & 6.00 & 4.66 & 4.15 & 0.45 \\
Have more than $\$ 40$ cash in your wallet & 5.15 & 3.66 & 3.36 & 0.23 \\
Argue with a friend or family member & 2.62 & 2.62 & 2.67 & -0.05 \\
Stay up past midnight & 3.46 & 6.21 & 6.13 & 0.08 \\
Watch at least an hour of television & 3.92 & 3.15 & 3.67 & -0.51 \\
Tell a lie & & & & \\
Pay someone a compliment & 2.77 & 2.77 & 3.05 & -0.28 \\
\hline & 5.46 & 4.97 & 4.54 & 0.44 \\
\hline
\end{tabular}

These results stand in contrast to those of Study 1, in which the valence of the event was unrelated to the past-future asymmetry in likelihood judgments. But these results should not be taken to mean that only highly positive events are judged to be more likely in the future than 
in the past. Among the items showing the largest past-future difference are "wearing red" $\left(M_{\text {diff }}=0.72, t(38)=3.26, p<.005\right)$ and "having a phone conversation lasting more than 30 minutes" $\left(M_{\text {diff }}=0.64, t(38)=\right.$ $1.98, p<.06)$ both of which seem to be fairly neutral behaviors. Indeed, when I asked a separate sample of 30 participants to classify each of the events in this study as positive, negative or neutral, $73 \%$ classified "wearing red" as neutral, and 70\% classified "having a phone conversation lasting more than 30 minutes" as neutral. Thus, it is likely that the observed positive correlation between event valence and the pastfuture asymmetry is due to a tendency to predict that negative events are unlikely to happen, rather than a tendency to predict that only positive events are likely to happen, in the future. The relationship between this finding and the findings of Study 1 will be discussed further below.

One limitation of Study 3 is that although I attempted to equate knowledge of the past and future by asking participants about what happened on a very specific date in the distant past and future, I cannot fully rule out an artifactual explanation of the results. In particular, it is possible that some participants knew that they had never engaged in a particular behavior in the past, regardless of specific date, but could not say for certain that they would not engage in that behavior in the future. These participants would be likely to show a past-future difference not because they judge uncertain future events as more likely than uncertain past events in general, but because they have specific knowledge of the past that does not extend to the future.

One piece of evidence arguing against this artifactual explanation comes from a survey I conducted using a separate sample of respondents 
$(n=41)$. Survey respondents were provided with the list of behaviors from Study 3 and were asked to indicate whether or not they had engaged in each of the behaviors sometime in the past two years. I reasoned that if most or all of the participants in this follow-up study had engaged in each behavior sometime in the past two years, it is unlikely that the results of Study 3 were driven by a subset of participants who had not done so. Only for three of the 12 behaviors did more than one participant indicate that they had not engaged in that behavior sometime in the past two years. Moreover, the size of the effect for these three behaviors - eating cereal for breakfast, cooking dinner, and feeling lonely - did not differ significantly from the size of the effect for the other nine behaviors (paired $t(38)=1.33, n s)$. Thus, although I cannot rule out the possibility that some participants in Study 3 had never engaged in one or more of the behaviors at any time in the past, I believe it is unlikely that the results of Study 3 can be entirely attributed to this artifactual explanation.

\section{Conclusion}

When people gaze into the future, they see a different world than when they peer into the past. In the future people see possibility; they see a world where the same event that was unlikely to occur in the past may yet occur in the future. Indeed, across three different studies, participants consistently judged uncertain future events to be more likely than identical past events, all other things being equal. In Study 1, participants thought a typical Cornell student would be more likely to experience a variety of positive and negative events in the coming week than that she had experienced those same events in the past week. In Study 2, participants thought it more likely that a mentally ill individual would 
attempt suicide if they were predicting his future behavior than if they were postdicting his past behavior. This effect occurred regardless of whether the prior base rate of suicide attempts for individuals with this illness was high or low. In Study 3, participants thought it more likely that they themselves would experience a variety of events on a specific date one year into the future than that they had experienced those same events on a specific date one year into the past.

Interestingly, the role of event valence in moderating this effect differed across studies. In Study 1 the valence of the event was unrelated to the past-future asymmetry, whereas in Study 3 the valence of the event was positively related to the asymmetry - participants in Study 3 were more likely to show the past-future asymmetry to the extent that the event they were judging was more positive (or at least less negative). Why might this be the case? One possibility is that the events in Study 3 were more extreme in valence than those of Study 1, and thus there was more of an opportunity for valence to play a role in moderating the effect. I believe this is unlikely, as the events in Study 3 are not noticeably more extreme than those in Study 1, an observation that is bolstered by a comparison of the variance in participants' mean positivity ratings across items in each of the two studies $(S D \mathrm{~s}=1.44$ and 1.31 for Studies 1 and 3, respectively).

A more likely explanation is that participants were more motivated to predict a positive future in Study 3, when they were forecasting their own fate, than in Study 1, when they were forecasting the fate of someone else. This hypothesis is consistent with a great deal of research on the tendency for people to hold overly optimistic beliefs about themselves and 
their prospects (e.g., Buehler et al., 1994; Epley \& Dunning, 2000; Newby-Clark \& Ross, 2003; Weinstein, 1980). If people are motivated to see their own futures as bright and rosy, they should tend to overestimate the likelihood of positive outcomes and to underestimate the likelihood of negative outcomes in the future. In the case of positive events, this would lead to an augmentation of the timing effect in likelihood judgments, as both the timing effect and the motivation to forecast a positive future would lead people to judge positive future events as more likely than equivalent past events. In the case of negative events, however, the motivation to forecast a positive future would conflict with the tendency to see uncertain events as more likely in the future than in the past, leading to a reduction in the timing effect. Neutral events should be unaffected by the motivation to forecast a positive future, and hence would show only the usual timing effect in likelihood judgments. This account seems to fit the results of Study 3 quite well.

If this reasoning is correct, we might expect the timing effect to be less reliable when people are predicting self-relevant outcomes than when they are predicting outcomes unrelated to the self, as the occurrence of the timing effect in self-relevant judgments will depend quite heavily on whether one is evaluating positive, negative, or neutral outcomes. I will return to this point in Chapter Five, when I discuss the boundary conditions of the timing effect in likelihood judgments. 
CHAPTER THREE:

\section{INTO THE GREAT WIDE OPEN}

Eddie waited 'til he finished high school

He went to Hollywood, got a tattoo

He met a girl out there with a tattoo too

The future was wide open

- Tom Petty, Into the Great Wide Open

In the last chapter I presented evidence indicating that people judge uncertain future events to be more probable than equivalent past events. Why might this be the case? As described in Chapter One, one potential explanation is that people associate the future (but not the past) with openness and possibility, and thus any particular event seems more possible (and hence more probable) in the future than in the past. Although casual observation suggests that people associate the future with openness more so than the past, this claim has not yet been tested empirically. Before examining whether this association is responsible for the timing effect in likelihood judgments, then, it is first necessary to test whether people do indeed associate the future with openness and possibility more so than the past.

To do so, I conducted a study in which I measured people's associations to past and future using both explicit and implicit measures. The explicit measure was a semantic differential scale in which participants rated the concepts of past and future on a series of bipolar attributes related to the concepts of openness and possibility on the one hand, versus determinism and fixedness on the other. The implicit measure was an adaptation of the Implicit Association Test (IAT; 
Greenwald, McGhee \& Schwartz, 1998), which has been used to measure a variety of implicit attitudes and beliefs, including intergroup bias, selfesteem, and consumer attitudes, just to name a few (Dasgupta \& Greenwald, 2001; Greenwald \& Farnam, 2000; Maison, Greenwald \& Bruin, 2001). In my version of the IAT, participants classified words as belonging to the categories of past versus future and open versus closed. I predicted that an implicit association between the future and the concept of openness would be revealed by a tendency to respond more quickly when future was paired with open (and past with closed) in the classification task than when future was paired with closed (and past with open).

\section{Study 4a: The Past-Future Semantic Differential}

\section{Method}

Fifty-five Cornell undergraduates completed the present study, which was distributed in a packet of unrelated surveys being collected by various researchers in the Social Psychology laboratory. Participants were asked to rate the concepts past and future on four 7-point semantic differential scales related to the concepts of openness and possibility (open-closed, certain-uncertain, fixed-malleable, determinedundetermined). To explore whether people also see the future in more positive terms than the past, I included two semantic differential scales related to the concept of positivity (positive-negative, dim-bright). These two sets of ratings were embedded within several filler items asking participants to rate other concepts unrelated to time on bipolar scales relevant to those objects (e.g., honest-corrupt and for the concept politicians, or important-unimportant for the concept education). The 
order of the two key concepts was counterbalanced, such that some participants first rated future and later rated past, whereas others rated them in the opposite order.

\section{Results and Discussion}

Participants' average ratings of past and future are displayed in Table 3.1. As predicted, participants rated the future as more open to possibility than the past on every one of the six measures. Specifically, in comparison to the past, participants judged the future to be significantly more open, uncertain, malleable, undetermined, positive, and bright (see Table 3.1 for the results of significance tests on these differences). The order of participants' judgments did not moderate these differences in ratings of past versus future. ${ }^{4}$ Thus, on an explicit level, participants reported seeing the future as relatively open and positive, and the past as relatively closed and negative.

It is interesting to note that the size of the past-future difference is much larger for the items related to openness (open, uncertain, malleable, and undetermined) than for the items related to positivity (positive and bright). Indeed, an analysis comparing the mean past-future difference across the four openness items to the mean past-future difference across the two positivity items revealed a significant difference, $M \mathrm{~s}=3.7$ and

\footnotetext{
${ }^{4}$ Although not central to my investigation, I conducted a factor analysis to examine how participants' ratings on these dimensions hung together when they judged the past and future. A principal components analysis with varimax rotation on the six ratings of the past yielded two factors. Factor 1 included open-closed, determinedundetermined, certain-uncertain and malleable-fixed whereas Factor 2 included positive-negative and bright-dim. The same analysis on the six ratings of the future also yielded two, albeit somewhat different, factors. Factor 1 included open-closed, positive-negative, and bright-dim whereas Factor 2 included determinedundetermined, certain-uncertain and malleable-fixed.
} 
$0.9, S D s=1.4$ and 1.4 for openness and positivity, respectively, paired $t(54)=11.52, p<.0005$. The future is much more open, uncertain, malleable, and undetermined than the past, but only a little brighter and a little more positive. Thus, it appears that the concept of openness is much more central to the distinction between past and future than is the concept of positivity.

Table 3.1

Mean ratings of past and future along six dimensions

\begin{tabular}{lcccc}
\hline \multicolumn{1}{c}{ Item } & Future & Past & Difference & Paired t-statistic \\
\hline Open & 6.15 & 2.53 & 3.62 & $16.61^{* *}$ \\
Uncertain & 5.84 & 1.93 & 3.91 & $18.23^{* *}$ \\
Malleable & 5.89 & 1.82 & 4.07 & $17.35^{* *}$ \\
Undetermined & 4.96 & 1.96 & 3.00 & $11.23^{* *}$ \\
Positive & 5.56 & 4.91 & 0.65 & $3.31^{*}$ \\
Bright & 5.58 & 4.47 & 1.11 & $4.70^{* *}$ \\
\hline
\end{tabular}

Note. After Bonferroni correction for multiple comparisons, t-statistics marked with a single asterisk $(*)$ are significant at the $p<.05$ level; those marked with a double asterisk $(* *)$ are significant at the $p<.005$ level.

\section{Study 4b: The Past-Future IAT}

\section{Method}

Participants were 53 members of two Cornell sororities who participated in this and several other short studies for a cash payment. The present study was run by two research assistants (each a member of one of the sororities), who set up a Dell Inspiron Notebook running 
Millisecond Inquisit software in a quiet spot in the sorority house, and recruited participants from the house to participate in the study.

The Past-Future IAT was designed using the guidelines set forth by Greenwald, Nosek and Banaji (2003). The IAT consisted of seven blocks of trials, with 20 trials in each of the five practice blocks and 40 trials in each of the two critical test blocks (see Table 3.2 for an overview of the IAT procedure). In each block, the words to be classified appeared one at a time in the center of the screen. Category labels were displayed for the duration of the block on the upper left- and right-hand corners of the screen. Participants were asked to classify the words by pressing a key on the left- or right-hand side of the keyboard to indicate whether the target word belonged in the category on the left or the category on the right.

Brief instructions were provided immediately before each block, and participants were provided with the list of words that belonged to each category at the beginning of the test. The Future words were future, tomorrow, and will be; The Past words were past, yesterday, and was; The Open words were open, yes, and possible; The Closed words were closed, no, and limited. Participants were asked classify these words as quickly as possible into the appropriate category without compromising accuracy. If a participant made a mistake (i.e., put a word into the wrong category), a red $\mathrm{X}$ appeared below the target word and the participant had to make the correct response to proceed. 
Table 3.2

Design of the Past-Future IAT

\begin{tabular}{ccccc}
\hline Block & Trials & Function & Left-key & Right-key \\
\hline 1 & 20 & Practice & Future words & Past words \\
2 & 20 & Practice & Open words & Closed words \\
3 & 20 & Practice & Future or Open & Past or Closed \\
4 & 40 & Test & Future or Open & Past or Closed \\
5 & 20 & Practice & Past words & Future words \\
6 & 20 & Practice & Past or Open & Future or Closed \\
7 & 40 & Test & Past or Open & Future or Closed \\
\hline
\end{tabular}

Note. The order of the pairings was counterbalanced across participants such that for some participants Future was paired with Open and Past with Closed on Blocks 3 and 4, but for other participants Future was paired with Closed and Past with Open on these blocks.

\section{Results and Discussion}

The IAT data were analyzed by computing the $D_{1}$ measure described by Greenwald et al. (2003), which equaled the mean difference in latency on trials for which Future was paired with Closed (and Past with Open) and those for which Future was paired with Open (and Past with Closed), divided by the overall standard deviation of these latencies. Positive numbers indicated a tendency to response more quickly when Future was paired with Open and Past with Closed than vice versa. Trials with response latencies greater than $10,000 \mathrm{~ms}$ were discarded, whereas those under 10,000 ms were included (even if errors were made). Latencies for both practice blocks (3 and 6) and test blocks (4 and 7) are 
included in this measure. $D_{1}$ has been shown to outperform the original IAT scoring procedure on a variety of metrics, including the magnitude of implicit-explicit correlations, sensitivity to known effects (such as ingroup bias), and resistance to the influence of prior experience with the IAT (Greenwald et al., 2003).

A one-sample t-test comparing the mean of participants' $D_{1}$ scores to zero revealed a significant IAT effect in the predicted direction, $M=$ $0.59, t(52)=10.71, p<.0005$. Participants were quicker to respond on trials in which Future was paired with Open and Past with Closed $(M=$ $812 \mathrm{~ms}, S D=195 \mathrm{~ms}$ ) than on trials in which Future was paired with Closed and Past with Open $(M=1055 \mathrm{~ms}, S D=251 \mathrm{~ms})$. This suggests that people associate the future with openness (and the past with fixedness) more strongly than they associate the past with openness (and the future with fixedness). There was also a marginally significant effect of order, such that participants for whom Future was first paired with Open (and Past with Closed) showed a larger IAT effect than those for whom Future was first paired with Closed (and Past with Open), $M_{D^{1}} \mathrm{~s}=$ 0.68 and $0.49, S D \mathrm{~s}=0.39$ and 0.40 , respectively, $t(51)=1.76, p<.10$. This order effect is similar to those that have been documented in prior research using the IAT (Greenwald et al., 1998).

These initial findings suggest that people do indeed associate the future with openness and possibility more so than the past, both at an implicit and at an explicit level. Thus, the association between the future and openness is a potential explanation for the tendency to believe uncertain future events are more probable than equivalent past events. This is not the only potential explanation, however. Another possibility is 
that people feel more accountable to the past than to the future, and thus are less likely to engage in a simple, confirmation-based strategy when judging past events than when judging future ones (Tetlock, 1992). That is, because past events are typically known or knowable, whereas future ones are not (yet), people may feel more pressure to make careful, accurate judgments about past events. When considering future events, on the other hand, people may be more likely to approach the judgment task in a more casual manner and engage in a confirmation-based approach typical of everyday hypothesis testing (Klayman \& Ha, 1987; Snyder \& Swann, 1978).

This accountability explanation seems unlikely, as it is not clear why feeling less accountable to the future should always lead to increases in the perceived likelihood of future events. Indeed, confirmatory thinking biases hypothesis testing toward confirming whatever hypothesis one is initially considering. In cases where the initial hypothesis is that an event is likely to occur, confirmatory thinking should lead to the perception that the event is even more likely to occur. But in cases where the initial hypothesis is that an event is unlikely to occur, confirmatory thinking should lead to the perception that the event is even less likely to occur. Not only is this prediction at odds with the overall findings of my first three studies, in which a wide variety of events were perceived to be more likely in the future than in the past, it is especially inconsistent with the results of Study 2, in which the focal event was judged to be more likely in the future than in the past even when the base rate of that event was low. If people are more likely to confirm their initial hypothesis when predicting the future than when postdicting the past, this should 
have led participants to judge the low base rate event to be less, not more, likely in the future.

\section{Study 5: Priming the Future}

It seems unlikely, then, that the results of Studies 1-3 are due to a tendency toward greater accountability and hence more deliberative thought when judging past events than when judging future events. But because this idea remains intuitively compelling (in some ways one should feel more accountable to the past than to the future), I designed a study to more carefully examine the accountability hypothesis. In this study, temporal information was not explicitly presented to participants, but was instead primed outside of conscious awareness. The accountability hypothesis requires that people explicitly consider the timing (i.e., past or future) of the event while evaluating information relevant to the likelihood of that event. If participants provide higher likelihood estimates when they are merely primed with the concept of future, despite having no knowledge of the temporal information and while engaging in a task that requires rapid responding, this would suggest that the past-future asymmetry is due not to greater deliberation when considering past events, but rather to the associations that spring to mind when the concepts of past and future are activated.

Thus, in Study 5 participants were led to believe that the purpose of the study was to see how easily people can detect subliminal stimuli. For this reason, they were told, they would be subliminally primed with a particular geometrical shape, and would rate the likelihood that a subsequently presented (supraliminal) target shape was the same as the shape that had been subliminally flashed at them moments before. In 
actuality, participants were subliminally presented not with geometrical shapes, but with words intended to prime the concepts of past, present or future. The "subliminal perception" cover story was intended to: (a) provide an explanation for the brief flashes participants would see onscreen, and (b) give the participants a context in which to make a series of likelihood judgments. If the timing effect in likelihood judgments is due to explicit feelings of accountability to the past, I should find no difference in participants' likelihood judgments between future prime trials and past prime trials. If, as I predict, the timing effect is due to the tendency to associate the future with openness and possibility, I should find that participants provide higher likelihood estimates when they are primed with future than when they are primed with past.

Moreover, I included a prime intended to activate the concept of "present" in order to examine whether the past-future asymmetry arises from a tendency to see future events as especially likely or a tendency to see past events as especially unlikely. I argue that people associate the future with openness and possibility, and it is this association that drives the past-future asymmetry. Thus, I predict that participants will provide higher likelihood estimates on future-prime trials than on past-prime or present-prime trials. I predict that these latter two types of trials will not differ from one another, as both the past and the present are already determined in a way the future is not.

\section{Method}

Participants were 36 Cornell undergraduates who participated in several short studies for extra credit in a psychology course. Upon arrival at the Social Psychology laboratory, participants were told that they 
would be completing a computerized "subliminal perception" task. They were told that on each trial, they would be subliminally presented with one of three shapes: a triangle, a circle, or a square. A target shape (also a triangle, circle or square) would then appear in the center of the screen. Their task was to indicate whether they thought the target shape was the same as the shape that was subliminally presented to them a moment before by pressing a number between 1 and 9, where 1 meant "not at all likely" and 9 meant "extremely likely." Participants were further told that although the task may seem difficult, they would do fine if they went quickly, relying on their initial, gut feeling on each trial.

Participants then began the task, which consisted of nine practice trials and 72 critical trials. On each critical trial, participants focused their attention on a string of nonsense letters (MZNBVZXCVB) in the center of the computer screen. After $300 \mathrm{~ms}$, this fixation point was replaced by the prime word ("past," "future," or "now"). 5 The prime remained on screen for $33 \mathrm{~ms}$, and was then masked by the same nonsense letter string for an additional $50 \mathrm{~ms}$. The target shape then appeared in the center of the screen, and remained on screen until participants entered a likelihood estimate. The nine practice trials were identical to the critical trials, except instead of a prime word, the fixation point was replaced for $33 \mathrm{~ms}$ by a different string of nonsense letters (ZXCVBNMZXC). Each of the three primes was presented on 24 separate trials, for a total of 72 critical trials. Each prime was paired an equal number of times with the three target shapes (square, circle, and triangle), resulting in nine prime-target

\footnotetext{
5 The prime "now" was selected instead of "present" because the word present has more than one meaning and might not be interpreted in the manner intended here.
} 
pairs that were each presented eight times over the course of the task. Trials were randomized for each participant.

Following the task, participants were probed for awareness of the primes using a funnel debriefing procedure (Bargh \& Chartrand, 2000). No participant reported seeing words (and indeed, quite a few reported seeing contours or outlines of shapes) during the subliminal presentations, and thus the data from all 36 participants are included in the analyses.

\section{Results and Discussion}

I tested my hypothesis, that likelihood ratings would be greater following "future" primes than following "past" or "now" primes (and that ratings for these latter two primes would not differ from one another), by averaging participants' likelihood ratings for targets following each type of prime (past, future, now) to create three composite measures of likelihood. A repeated measures ANOVA using the contrast weights 2, $-1,-1$ for future, past, and now, respectively, revealed a significant contrast, $F(1,35)=4.99, p<.05$. As predicted, participants provided higher likelihood estimates when primed with the word future $(M=5.41$, $S D=1.19)$ than when primed with the words past $(M=5.23, S D=1.08)$ or now $(M=5.19, S D=1.07)$. The results of the contrast were confirmed by simple effects tests, which indicated that likelihood estimates following the future prime were significantly greater than those following the now prime, paired $t(35)=2.26, p<.05$. The difference between the future prime and the past prime, while in the predicted direction, did not quite achieve statistical significance, paired $t(35)=1.60, p=.12$. Finally, estimates following the past prime and the now prime were not significantly different from one another, paired $t(35)<1, n s$. 
These results have several important implications. First, they more fully rule out the hypothesis that the timing effect in likelihood judgments is due to greater accountability, and hence more careful deliberation, when contemplating the past than when contemplating the future, as the effect obtains even when the concepts of past and future are merely primed, and are not explicitly linked to the judgment task. Second, they suggest that the asymmetry is driven by a tendency to see future events as especially likely, and not a tendency to see past events as especially unlikely, relative to the present. Third, they support the hypothesis that the past-future asymmetry is driven by an associative process, in which activating the concept of future further activates associated concepts, such as those of "openness" and "possibility."

Study 6: Manipulating the Future

Study 5 provided indirect support for the claim that people judge future events to be more likely than past events because they associate the future with openness and possibility. In order to obtain more direct evidence for this hypothesis, I conducted a study in which I actively manipulated participants' beliefs about the future. If people judge future events to be more likely than equivalent past events because they see the future as more open than the past, then convincing participants that the future is not open, but rather is already entirely determined, should eliminate the past-future difference in likelihood judgments. Thus, in Study 6, I presented participants with a fake newspaper article, ostensibly printed in The New York Times, describing scientists' current views of the nature of time. Some participants received an article arguing that the future is "wide open," whereas others received an article arguing that the 
future is "a closed book." Participants then made a series of judgments about the likelihood of past or future events. I predicted that participants who read that the future is open would show the usual tendency to see future events as more likely than equivalent past events, but that this effect would be eliminated among those who read that the future is a closed book. If obtained, these results would provide direct evidence that the timing effect is due to a tendency to believe in an open future.

\section{Method}

Participants were 62 Cornell undergraduates (51 female) who participated in a set of short, unrelated studies in exchange for extra credit in their psychology course. The present study occupied the last spot in the experimental session. Participants were asked to complete a packet of materials described as a set of unrelated questionnaires. In actuality, this packet contained the manipulation of participants' associations to the future, the likelihood judgment task, manipulation checks, and several filler questionnaires meant to disguise the connection between the different components of the study.

The manipulation of participants' associations to the future appeared first in the packet, and consisted of a fake newspaper article describing the implications of recent scientific discoveries for the way in which scientists think about time. Participants were asked to simply read the article, as they would be asked some questions about it later in the packet. Two versions of this article were created - one that described the future as "wide open," and another that described the future as "a closed book." More specifically, the Open Future article argued that given the sheer number of factors that influence any given event, it is virtually 
impossible to know for sure what the future will bring. The Closed Future article, on the other hand, argued that because the universe operates according to the principle of cause and effect, the future is already determined by the events of the past and present (see Appendix for the full text of the articles). Thus, participants reading the former article were primed with the concept of an open future, whereas those reading the latter were primed with the concept of a closed, or predetermined, future.

After reading the article, participants moved on to a filler questionnaire, followed by the main dependent measure, a modified version of the "Everyday Events" questionnaire used in Study 1. The questionnaire was identical to that used in Study 1 except the problematic "hiking" item was eliminated (see Footnote 2). Thus, participants were asked to judge the likelihood that Jen either had experienced each of 11 events in the past week, or would experience each those same 11 events in the coming week. As in Study 1, participants made these judgments on 7point scales anchored at 1 ("extremely unlikely") and 7 ("extremely likely"). After completing these measures, participants moved on to the next page in the packet, which asked them some questions about the article they read. This set of questions contained a manipulation check, in which participants were asked to indicate which of two statements best described the article they read. These statements were: "The future is wide open" and "The future is a closed book." The manipulation check

\footnotetext{
${ }^{6}$ All but two participants correctly chose the statement that best described the article they had read. Because the responses of these two participants did not differ from those of participants who correctly identified the topic of the article, and because it
} 
was followed by several filler items asking participants to rate how interesting and well written the article was, which in turn were followed by two items asking participants to report their own beliefs about the future. Specifically, participants were asked to rate their agreement with the following: "Anything can happen in the future" and "The future is constrained by the past and present." These ratings were made on 7-point scales anchored at 1 ("totally disagree") and 7 ("totally agree").

Results and Discussion

As in Study 1, ratings for each event were normalized and the resulting z-scores were averaged to form a composite measure of likelihood. A 2 (article: open future vs. closed future) x 2 (timing: past vs. future) ANOVA on this composite revealed a significant interaction between the content of the article and the timing of participants' judgments, $F(1,58)=4.49, p<.05$. This interaction is displayed in Figure 3.1.

Follow-up comparisons using the error term from the ANOVA revealed that participants who read that the future is wide open showed the usual tendency to judge future events as more likely than equivalent past events, $M_{\text {future }}=.11, S D_{\text {future }}=.23 ; M_{\text {past }}=-.13, S D_{\text {past }}=.51 ; t(58)=$ $1.82, p=.07$. Participants who read that the future is a closed book, on the other hand, did not judge future events to be more likely than equivalent past events. If anything, these participants appear to judge future events to be less likely than past events, although this difference is not significant, $M_{\text {future }}=-.10, S D_{\text {future }}=.35 ; M_{\text {past }}=.05, S D_{\text {past }}=.37 ; t(58)=$ 
$1.17, n s$. Looking at the data another way, participants who read that the future is open judged future events to be more likely than participants who read that the future is determined, $t(58)=1.72, p=.09$. The content of the article did not affect participants' judgments of the past, $t(58)=1.24$, $n s$.

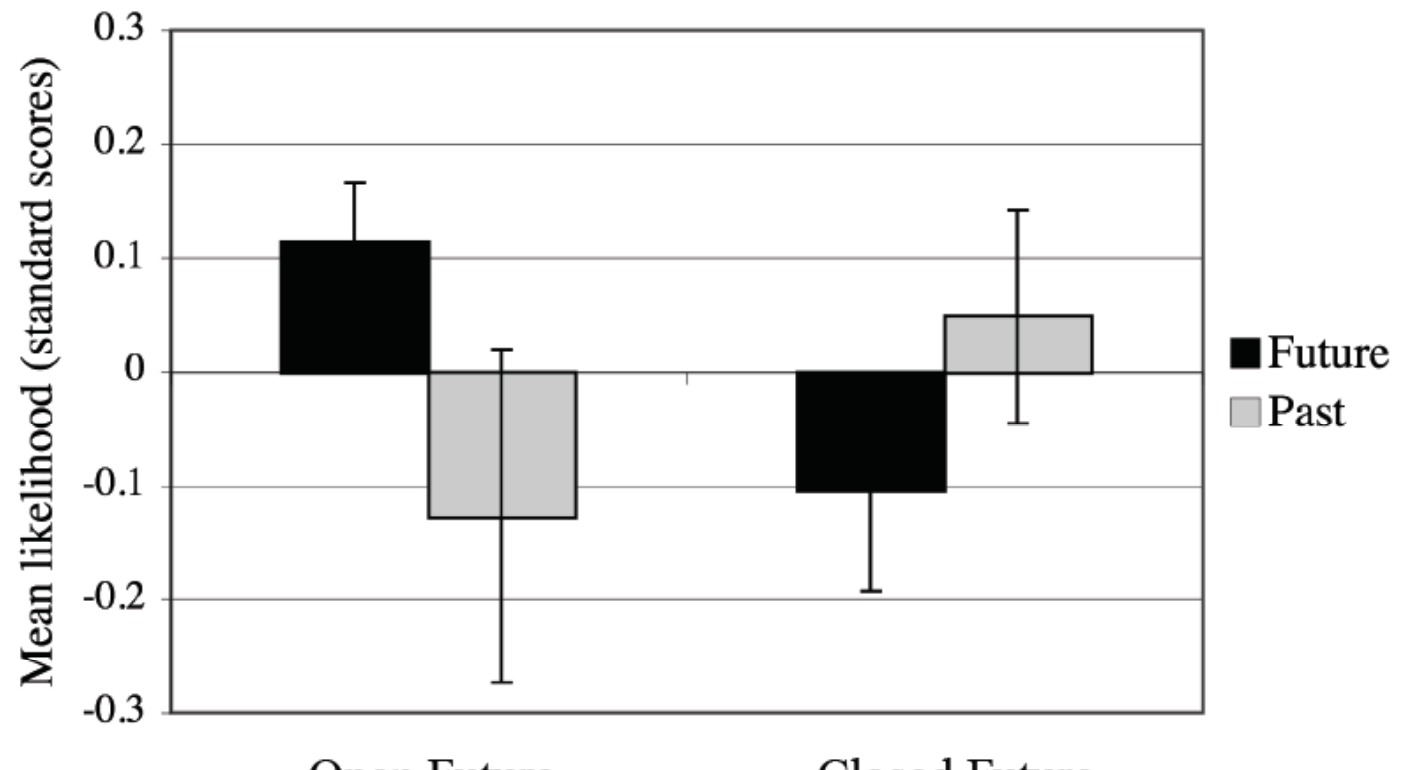

Open Future

Closed Future

Article Manipulation

Figure 3.1

Mean likelihood judgment as a function of the timing of the events and article manipulation.

Was the effect of the article manipulation on the timing effect in likelihood judgments mediated by a change in participants' explicit beliefs about the openness of the future? The two items tapping participants' own beliefs about the future were not highly related $(\alpha=.54)$ and thus are analyzed separately. Participants who read that the future is 
open were marginally more likely than those who read that the future is closed to agree with the statement, "Anything can happen in the future" $\left(M_{\text {open }}=5.7, S D_{\text {open }}=1.1 ; M_{\text {closed }}=5.2, S D_{\text {closed }}=1.5 ; t(60)=1.68, p<.10\right)$.

Contrary to expectations, however, participants who read that the future is open were as likely as those who read that the future is closed to agree with the statement, "The future is constrained by the past and present" $\left(M_{\text {open }}=4.0, S D_{\text {open }}=1.5 ; M_{\text {closed }}=3.8, S D_{\text {closed }}=1.6 ; t(60)<1, n s\right)$.

Even though the effect of the article manipulation on participants' belief that "anything can happen in the future" was only marginally significant, I conducted a mediational analysis to examine whether the change in this belief might mediate the effect of the article manipulation on the tendency to see future events as more likely than equivalent past events. The data did not meet the requirements for mediational analysis, however, in that the proposed mediator (a belief that anything can happen in the future) did not interact with the timing manipulation to significantly predict the dependent measure (likelihood estimates), $\beta=.092, t(58)=$ $1.25, n s$. Thus, while the change in this belief parallels the change in the past-future asymmetry, the former does not mediate the latter.

The results of Study 5 support the argument that the belief in an open future is causally related to the timing effect in likelihood judgments, as priming participants with the concept of a "closed" rather than an "open" future completely eliminated the past-future asymmetry. Interestingly, participants' explicit beliefs about the extent to which the future is open versus closed did not mediate this change in likelihood judgments for past and future events. It is possible that the self-report items I used were not sensitive enough to pick up on the changes in 
participants' associations to the future induced by the article manipulation. It is also possible, however, that the article changed participants' associations at a more implicit level, such that they could not accurately report on this change. Either way, simply having participants read an article arguing that the future is a closed book eliminated the tendency to judge future events as more likely than past events, suggesting that this phenomenon arises from an association between the future and openness or possibility.

\section{Conclusion}

Like Eddie in Tom Petty's now-classic ode to youth and rebellion, many people see the future as wide open. They also see it as undetermined, malleable, uncertain, positive and bright, at least in comparison to the past. Because people associate the future with openness and possibility more so than the past, they tend to see any particular uncertain event as bit more possible, and hence a bit more probable, in the future than in the past. Indeed, these associations seem to be so strong that incidental reminders of the future, even those that people encounter subliminally, are enough to prompt people to judge uncertain events in the world around them to be more likely. Might these associations to the future lead to other consequences beyond the realm of likelihood judgments? It is this question that I turn to in the next chapter. 


\section{CHAPTER FOUR: \\ BEYOND LIKELIHOOD}

In Chapter Three, I presented data suggesting that people see the future very differently from the way they see the past. The future tends to be seen as open, malleable, uncertain and undetermined, whereas the past tends to be seen as closed, fixed, certain and determined. Moreover, the future is relatively more positive and bright, whereas the past is relatively more negative and dim. Do these associations to past and future have consequences beyond the domain of likelihood judgment?

In this chapter I report the results of two studies exploring this question. In the first, I examined whether participants estimating the percentage of their peers endorsing a particular belief would provide higher estimates if they were predicting future beliefs than if they were postdicting past beliefs. If people see the future as more open than the past, this should have implications not just for likelihood estimates, but for any type of judgment that requires an assessment of what is possible. Thus, I asked participants in Study 7 to estimate the percentage of respondents who, in an opinion survey, would agree with one of two complementary attitudinal statements. If people make such a judgment by asking themselves, "Would people agree with this?" they should be predisposed to answer "Yes" and thus provide higher estimates if they are predicting future agreement than if they are postdicting past agreement. By including two complementary attitudinal statements, this study also allowed me to examined whether the tendency to give higher estimates to future events than to past events can lead people to believe, paradoxically, 
that two complementary focal events are both more possible in the future than in the past.

Study 7: Estimating the Beliefs of Others

\section{Method}

Sixty volunteers were recruited at public locations on the Cornell campus and asked to complete a short questionnaire. Participants were presented with one of two attitude statements regarding capital punishment and asked to indicate, in a forced choice format, whether they agreed or disagreed with the statement. Half of the participants were presented with an anti-capital punishment statement ("I believe the death penalty should be abolished in the U.S."); the other half were presented with a pro-capital punishment statement ("I believe the death penalty should continue to be used as a form of punishment in the U.S."). After indicating whether they agreed or disagreed with the statement, participants were asked to estimate the percentage of respondents in a Psychology department survey who would agree with the statement. Half of the participants were asked to suppose that the survey would take place the following month whereas the other half were asked to suppose that the survey took place the previous month.

Results and Discussion

Participants tended to oppose capital punishment, as $63.3 \%$ of those presented with the anti-capital punishment statement agreed with it, whereas only $40 \%$ of those presented with the pro-capital punishment statement did so. This difference was marginally significant, $\chi^{2}=3.27, p$ $<$.10. Participants' estimates of their peers' attitudes were analyzed via a 2 (statement: pro vs. con) x 2 (self: agree vs. disagree) x 2 (timing: past 
vs. future) ANOVA. This analysis revealed the predicted main effect of timing, $F(1,52)=13.57, p<.001$. Participants estimated that a higher percentage of their peers would agree with the statement if the survey had yet to take place $(M=61.5 \%, S D=15.9 \%)$ than if it had already taken place $(M=44.1 \%, S D=16.8 \%)$, regardless of which statement participants were evaluating. No other effects approached significance. Thus, participants thought that a greater percentage of their peers would be pro-capital punishment, and that a greater percentage would be anticapital punishment, if they were predicting future responses than if they were postdicting past responses (See Figure 4.1). ${ }^{7}$

\footnotetext{
${ }^{7}$ Some readers may be surprised to learn that I did not find evidence of a false consensus effect in the data, whereby those who favored capital punishment would expect others to be relatively more pro-capital punishment than would those who opposed capital punishment (Ross, Greene, \& House, 1977). I believe the lack of a false consensus effect can be traced to the particular method used to elicit participants' responses. I asked participants to indicate their own opinions immediately before estimating the opinions of others, which may have drawn their attention to the possible influence of this factor on their estimates and led them to discount it. Indeed, several researchers have noted that false consensus effects are greatly attenuated when participants' own choices are elicited before, not after, their predictions about the choices of others (Fabrigar \& Krosnick, 1995; Mullen et al., 1985).
} 


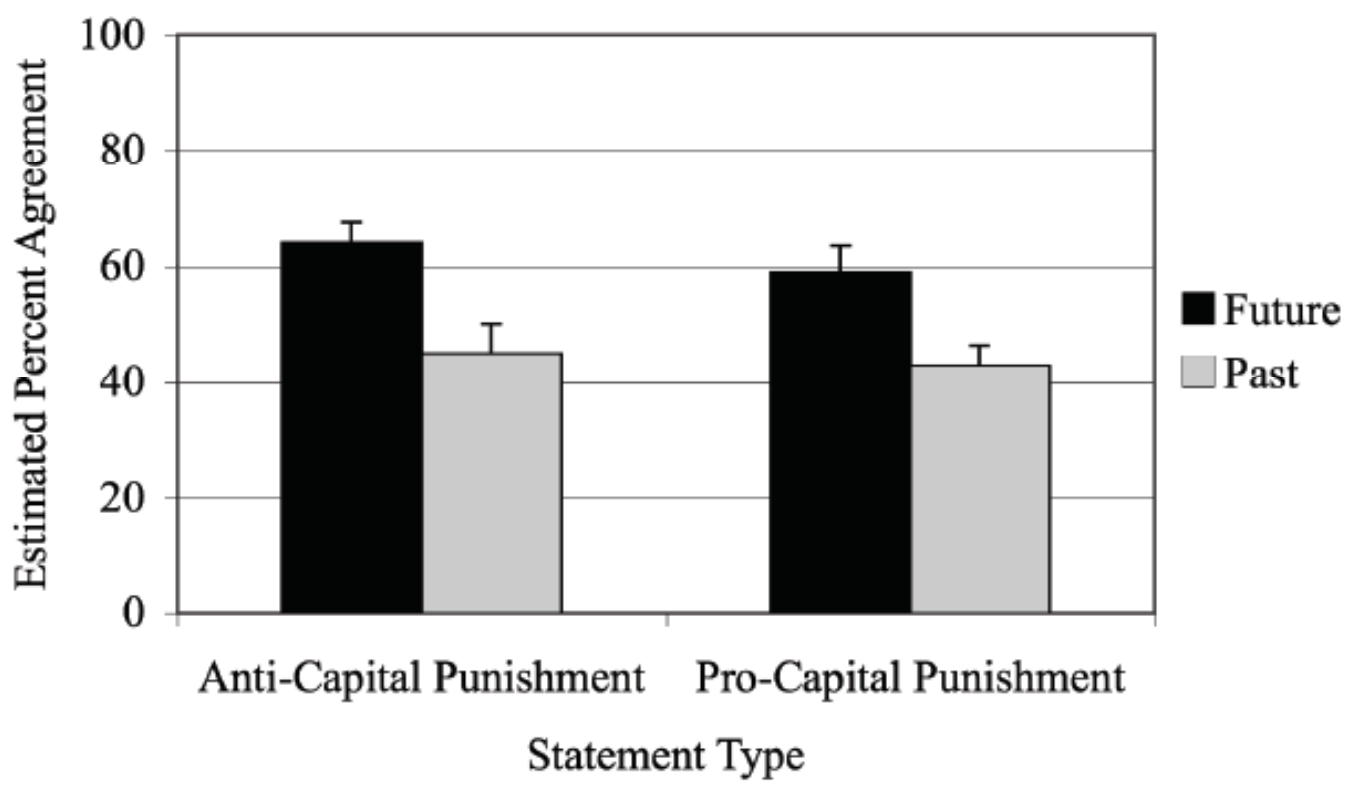

Figure 4.1

Mean estimates of the percentage of Cornell students who would agree with each statement, by timing condition.

These results are interesting for two reasons. First, they extend the timing effect beyond likelihood estimates to other types of judgments. Second, they provide the first evidence that the timing effect may be considered a bias. The statements participants evaluated were entirely complementary, so to the extent that they believed more people would agree with one statement in the future, they should have believed that fewer people would agree with the other statement. If a greater percentage of the population will be pro-capital punishment in the future, for example, then a smaller percentage of the population will be anticapital punishment. Instead, participants estimated that more people would agree with each statement in the future - that a greater percentage would be pro-capital punishment and a greater percentage would be anti- 
capital punishment. In this way, the tendency to believe in an open future appears to introduce a bias into people's judgments.

Study 8: Representing Time

The results of Study 7 suggest that the tendency to see the future as more open than the past has consequences for judgments beyond the domain of likelihood. But this is not the only association to the future that might have consequences for judgments and behavior. In addition to reporting that the future is more open than the past, people also report that the future is relatively bright and positive whereas the past is relatively dim and negative. If people do in fact hold these associations to past and future, we should be able to see traces of these associations in the way people depict the passage of time. That is, when people pictorially depict the distant past, they should depict it as a relatively dark place, whereas they should depict the more recent past, the present, and the future as increasingly brighter.

One way to test this hypothesis is to examine how people represent the passage of time in timelines. Historical and geological timelines often use color to enhance the look of the timeline and aid in interpretation by showing gradients of color from one end of the timeline to the other. When people use varying shades of color to depict the passage of time in timelines, do they naturally tend to use darker colors to represent the distant past and increasingly lighter colors to represent the more recent past, the present, and the future? In order to answer this question, I conducted a two-part study. Study 8a was an archival study of color timelines available on the Internet that were coded for the gradient of color used to represent the transition from past to present and/or present to 
future. If people do indeed associate the past with darkness and the future with brightness, I should find that more of these timelines use color gradients that progress from relatively dark to relatively light colors than progress from relatively light to relatively dark ones. Study $8 \mathrm{~b}$ was a behavioral study in which participants were asked to color in a blank timeline using four colored pencils of varying shades of green. Again, if people associate the past with darkness and the future with brightness, I should find that participants start with the darkest shade of green to illustrate the distant past, and use increasingly lighter shades to illustrate the progression of time across the timeline.

Study 8a: Archival Timeline Study

\section{Method}

The following keywords were entered, one at a time, into the image search function of a popular Internet search engine: "timeline," "timelines," "timeline of history," "timelines of history," "historical timeline," "geological time chart," "geological timeline," "timelines of world history," "evolution chart," "evolution timeline," and "geological time scale." 8 Only the first 100 image results per search were considered (for a total of 1100 images). Of these, images of timelines displaying progressively lighter or darker coloration in either direction (light to dark or dark to light) were selected for inclusion in the study. A research assistant coded each timeline for whether the color gradient became progressively lighter or darker as time progressed from the distant past to the present and/or future, and a second rater verified the direction of the color change. In order for a timeline to be coded as progressing from

\footnotetext{
${ }^{8}$ This search engine can be accessed at http://images.google.com.
} 
light to dark (or vice versa), it had to show a consistent change from lighter to darker shades of color (either the same color or different colors that varied in lightness). Images containing ambiguous color gradients that did not clearly progress from dark to light or light to dark were excluded from analysis.

Results

Thirty-eight timelines were identified that showed a clear transition from lighter to darker shades of color or from darker to lighter shades of color. This sample included historical and geological timelines that represented the distant past up to the present, as well as religious and technological timelines that began in the recent past or present and transitioned to predictions about the future. Of the 38 timelines identified, $27(71.1 \%)$ were consistent with the hypothesis that the colors used would become progressively lighter as the timeline approached modern day (and/or progressed into the future), whereas 11 (28.9\%) were inconsistent with this hypothesis in that the colors used became progressively darker as the timeline approached the present (and/or continued into the future). ${ }^{9}$ This pattern of results deviated significantly from chance, $\chi^{2}=6.74, p<$ .01 .

Study 8b: Behavioral Timeline Study

The results of Study 8a suggest that people tend to naturally represent the progression of time as one that begins in darkness and gets brighter as it advances, and is consistent with the idea that people see the

\footnotetext{
${ }^{9}$ Of the 27 timelines progressing from dark to light, 23 depicted past events and 4 depicted past through future events. Of the 11 timelines progressing from light to dark, 8 depicted past events, 2 depicted past through future events, and 1 did not depict a particular time period (instead this timeline showed the life course of a particular species of fish).
} 
past as relatively dark or dim, and the future as relatively bright. It is possible, however, that the timelines published on Internet websites are not representative of the way people are normally inclined to represent time. Thus a second set of data was collected from a group of participants who were asked to color in a blank timeline. Again, if people are naturally inclined to see the progression of time as one from the darkness of the past to the brightness of the future, these participants should select darker colors for the earlier portion of the timeline and lighter colors for the later portion.

\section{Method}

Twenty volunteers were recruited at various locations in Ithaca, NY and were asked to complete a short questionnaire. Those agreeing to participate were given a black-and-white copy of a geological timeline, and were asked to color in the timeline using a set of four green colored pencils that varied in shade. Specifically, participants were told:

This is a geological timeline representing the last 250 million years on Earth, which included the rise and fall of the dinosaurs and the evolution of humans. Timelines like this one are often presented in color, and as you can see right now this one is just black and white. What I would like you to do is to give the timeline a splash of color. So please use these pencils to color in the timeline however you would like, as though you were preparing to use it in a presentation.

The four colored pencils participants were given varied in shade such that they included a very light green, a moderately light green, a moderately 
dark green, and a very dark green. The timeline consisted of a white box with a black border divided into four main segments (see Figure 4.2). The segments were labeled with the appropriate periods of the Mesozoic era (Triassic, Jurassic, Cretaceous) and the fourth segment was simply labeled as the Cenozoic era. Several arrows pointed to different areas of the timeline and were labeled with major events that occurred at that time (such as the rise of the dinosaurs and the evolution of humans).

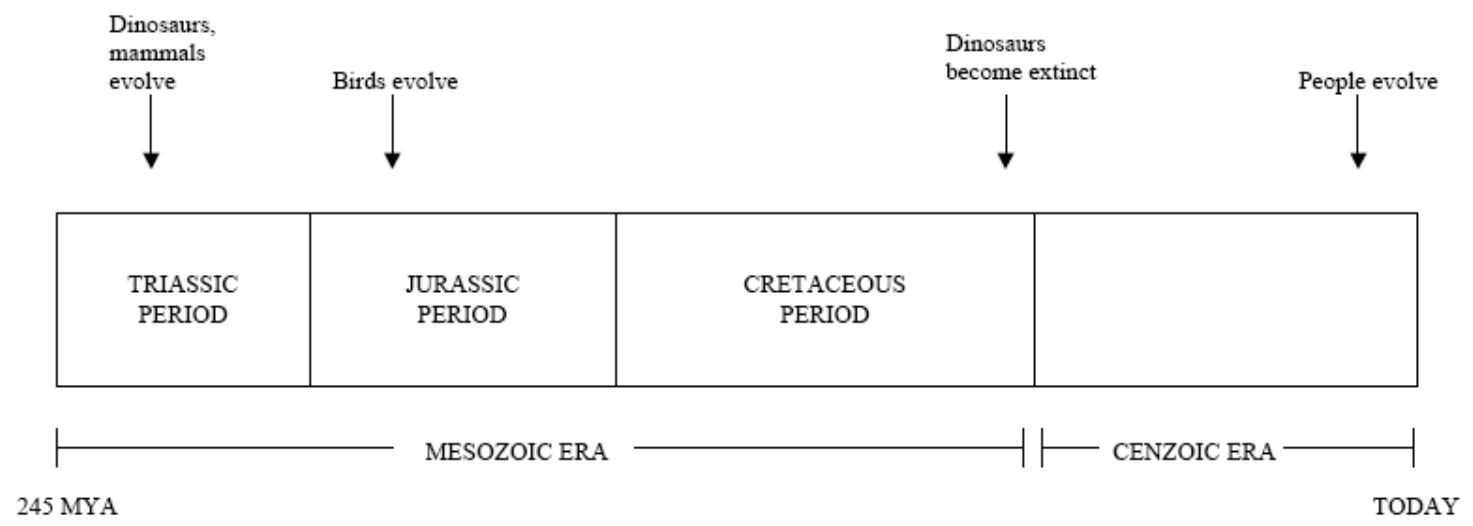

Figure 4.2

Timeline that participants were asked to illustrate with color in Study $8 b$.

Results and Discussion

Eight of the 20 participants colored in the timeline in a way that did not consistently progress from light to dark or from dark to light, and are excluded from the analysis. Of the 12 participants who did show a consistent progression of shading, $10(83.3 \%)$ colored in the timeline in the predicted direction, starting with the darkest shade of green for the earliest era, and using progressively lighter shades of green to decorate the remaining eras. The remaining two participants $(16.7 \%)$ colored in the 
timeline in the opposite direction, starting with the lightest shade of green and using progressively darker shades to show more recent time periods. This pattern deviates significantly from chance according to a binomial test, $p<.05$. Thus, a significant majority of the participants who depicted the passage of time using a consistent color gradient did so by progressing from relative darkness to relative lightness. This is again consistent with the idea that people associate the past with darkness and the present and/or future with brightness.

\section{Conclusion}

The results of two studies suggest that the tendency for people to see the past and future in very different ways extends beyond the realm of likelihood judgments. Participants asked to estimate the percentage of their peers endorsing a particular attitude statement thought that more of their peers would endorse the statement in the future than in the past, regardless of the actual content of the statement. This suggests that the tendency to see the future as open might have implications for a wide variety of judgments and behaviors. Indeed, people may simply see everything as bigger in the future than in the past. That is, to the extent that the future is seen as open and expansive, it may loom larger in the mind than the past, and hence future events may simply seem bigger than past events. If this were true, we might expect that participants asked to estimate a variety of sums or quantities would provide larger estimates for future events than for past events. This is a possibility worthy of future research.

An additional study examined whether the tendency to see the past as relatively dark and the future as relatively bright would have 
implications for the way people depict the passage of time. An archival analysis and a behavioral study both showed that when people use color gradient in historical and geological timelines to illustrate the passage of time, they tend to favor gradients that progress from dark to light over those that progress from light to dark. This suggests that people tend to think about time as a journey from the darkness of the past to the brightness of the future. This conclusion should be considered tentative, however, as the majority of the timelines in Study 8a focused on the past through the present, as did the timeline participants were asked to illustrate in Study 8b. Thus, it may be more appropriate to conclude that people see the past as darker than the present than to conclude that people see the future as brighter than the past. Although the subset of timelines that depicted future events in Study 8a agreed with the overall pattern of results, a larger sample of future-oriented timelines should be examined before making any strong conclusions about the way in which people depict the future. Moreover, the procedure used to select timelines in Study 8a did not allow for the inclusion of timelines that depicted the present as brighter than both the past and the future. Although a cursory inspection of the original search results suggests that such timelines appear rarely if at all, this possibility should be examined more carefully in future research.

These caveats aside, it would be interesting to explore whether the tendency to see the past as relatively dark and the future as relatively bright might appear in artists' depictions of past and future events, or in people's own imaginations. When people mentally visualize future events, do they literally "see" a brighter image than when they visualize 
past events? These are just a few of the possible extensions of this work into domains beyond that of likelihood judgments. Given the sheer number of associations people have to past and future, we might expect to find that the temporal contexts of events have a wide variety of influences on how people perceive those events. Some of these potential influences will be discussed in the next chapter, when I consider future directions for this work. 


\section{CHAPTER FIVE: \\ GENERAL DISCUSSION}

I began this dissertation with a question: What do people see when they gaze into the future? The research documented here suggests that they see a world open to possibility. And because people associate the future with openness and possibility, they tend to see uncertain future events as more likely to occur than equivalent past events, all else being equal. In Chapter Two, I documented this temporal asymmetry in likelihood judgments. In three studies, participants judged uncertain future events to be more likely than equivalent past events. This effect proved to be largely independent of the valence or prior base rate of the event, at least when participants judged non-self-relevant events. When participants judged self-relevant events, the timing effect was moderated by event valence such that participants were more likely to show the pastfuture difference in likelihood estimates as the events in question became more positive (or at least, less negative).

In Chapter Three, I demonstrated that this temporal asymmetry arises from a tendency to see the future as more open than the past. First, participants rated the future as more open, uncertain, malleable, and undetermined than the past, and were quicker to associate the future with the concept of "open" and the past with concept of "closed" than they were to associate future with closed and past with open. Second, merely priming participants, outside of conscious awareness, with the concept of the future elevated likelihood judgments relative to priming participants with the concepts of the past or present. This suggests the timing effect is due to associations made accessible when the concept of the future is 
activated, and not to explicit feelings of accountability to the past. Finally, manipulating participants' associations to the future by convincing them that the future is not open but is instead a closed book, determined by the events of the past and present, entirely eliminated the past-future difference in a subsequent likelihood estimation task. This finding demonstrates the causal role of the belief in an open future in producing the timing effect in likelihood judgments, as eliminating this belief eliminated the effect.

In Chapter Four, I explored two extensions of this work, showing that the future-openness association has consequences not only for likelihood judgments but for related judgments and behaviors as well. In one study, participants believed more of their peers would agree with a particular attitude statement in the near future than in the recent past, regardless of the content of the attitude statement. In another, an archival analysis and a behavioral study of the way in which people visually represent time using timelines suggested that people associate the distant past with darkness but the recent past and future with lightness.

The findings reported here should not be taken to mean that any event will be seen as more probable in the future than in the past. I do not doubt, for example, that most people believe an individual had a greater chance of dying from polio 60 years ago than he or she will have 60 years from now. Judgments about events whose future occurrence is limited by historical trends are not likely to conform to the pattern of judgment documented here. Instead, I would expect to see the effects reported here when events are uncertain, and there is no factual basis to believe that the events in question are more probable at one time than at another. So, for 
example, a couple may be more concerned about their teenage son throwing a party while they are away on vacation in the days leading up to their departure than they would be upon returning home. A job candidate may feel more confident that he or she will land the job before the hiring committee meets to make a decision than after the committee meets. Voters may believe a particular candidate is more likely to win the election if they are asked to forecast her chances of victory before the polls close than if they are asked just after the polls have closed. Because people's expectations and beliefs about events guide their behavior, the temporal location of an event may have important implications for how people behave in the context of that event. If voters see the chances of their preferred candidate winning the election as higher before the polls close, they may be less likely to take time out of their busy schedules to cast their vote - a decision they may come to regret soon afterward.

\section{Alternative Explanations}

I have argued that the timing effect in likelihood judgments (and beyond) is due to a tendency to associate the future, but not the past, with openness and possibility. Are there any other possible explanations for this effect? One potential alternative explanation is that people feel more accountable to past than to future events, and thus they are more likely to engage in careful, deliberative reasoning, and less likely to use simple, confirmation-based strategies, when evaluating the likelihood of past events than when evaluating the likelihood of future ones. Although this hypothesis has some intuitive appeal, there are a number of reasons to doubt its validity. As noted in Chapter Three, in order for this accountability hypothesis to explain the timing effect in likelihood 
judgments, it would have to be the case that people always start with the hypothesis that an event is likely to occur. Otherwise, why would a tendency to engage in more confirmatory thinking when evaluating future events than when evaluating past events lead to consistently higher likelihood estimates for future events? Because participants in Study 2 showed the past-future difference in likelihood estimates even when evaluating a low base rate event (for which they are likely to start with the hypothesis that the event is unlikely to occur) it cannot be the case that people engage in more confirmatory thinking when judging future events than when judging past events. Moreover, I found in Study 5 that merely priming participants, outside of conscious awareness, with the concept of future elevated likelihood estimates relative to priming participants with the concept of past. It is unlikely that these results could be explained by feeling accountable to the past, as participants were unaware of the timing of information, and were engaged in a task that required rapid responding (such that any kind of deliberation was unlikely).

My claim that the accountability hypothesis is unlikely to explain the findings presented here is bolstered by the results of a study I conducted using a paradigm developed by Snyder and Swann (1978). In this paradigm, participants choose questions to ask of a target person in order to test the hypothesis that the target is extraverted, or to test the hypothesis that the target is introverted. Snyder and Swann found in their original study that participants were biased by whichever hypothesis they were asked to evaluate, such that those asked to determine whether or not the target was extraverted were more likely to choose questions that would elicit extraverted answers, and less likely to choose questions that 
would elicit introverted answers, than were those asked to determine whether or not the target was introverted.

In my adaptation of this paradigm, I asked participants $(n=128)$ to determine either how the target would score on an upcoming personality test measuring introversion-extraversion, or how the target did score on a recent personality test measuring this construct. If people approach the future with a more confirmation-oriented mindset than they approach the past, I should have found that participants were more likely to choose questions that would confirm whichever hypothesis they were asked to test (i.e., extraversion or introversion) if the personality test was still in the future than if the test was in the past. I did not find this to be the case, however. Although I replicated the results of Snyder and Swann (1978), finding that participants were more likely to choose introversion-eliciting questions when they tested the hypothesis that the target was an introvert but were more likely to choose extraversion eliciting-questions when they tested the hypothesis that the target was an extravert, the timing of the personality test (past or future) failed to moderate each of these effects. Using an adaptation of a well-established paradigm, then, I did not find evidence that people display more of a confirmation bias when evaluating future events than when evaluating past events.

Aside from the accountability hypothesis, are there any other potential alternative explanations that might account for the timing effect in likelihood judgments? One candidate has to do with people's affective reactions to past and future events. Recent research indicates that people experience more affect in the present when thinking about future events than when thinking about past events (Van Boven \& Ashworth, 2006). 
And because future events are more affectively arousing, people attach greater value to them (Caruso, Gilbert \& Wilson, 2007). One may ask whether these effects may explain the findings documented here. Is the tendency to see future events as more likely than equivalent past events due to the fact that future events are more affectively arousing (and people misinterpret this arousal to mean those events are especially likely to occur)?

Although I do not have any data that speak directly to this question, I think this is unlikely to be the case. First of all, many of the events I asked participants to judge were rather mundane, everyday events that seem unlikely to pack much of an affective punch. In Study 1, for example, participants were asked to judge the likelihood that Jen would engage in activities such as calling her parents, doing her laundry, and going to the gym. Similarly, in Study 3, participants judged the likelihood that they themselves would wear the color red, eat cereal for breakfast, and have a phone conversation lasting more than 30 minutes. It seems unlikely that participants would experience much emotion when imagining any of these events, regardless of what time period they were considering. Moreover, the affect account can't explain why exposing participants in Study 5 to an argument that the future is predetermined eliminated the past-future difference in likelihood judgments. Thus, it seems unlikely that differences in affective arousal can explain the findings documented here. Instead, my findings and those documented by Van Boven, Caruso and colleagues seem to be parallel effects that converge to suggest that the future is "bigger," that it looms larger in the mind, than does the past. 
One may also ask whether the timing effect in likelihood judgment is due to differences in the level at which people construe past versus future events. Might it be the case, for example, that people construe future events at a more abstract level than past events, and that events construed at a more abstract level are perceived to be more likely than those construed at a more concrete level? Although there is some data to indicate that people construe hypothetical future events at a more abstract level than real past events, it is not clear that this effect would continue to hold if information about past and future events was held constant (Kane, Van Boven \& McGraw, 2007).

Moreover, there is no evidence that high-level construals are associated with higher probability estimates. If anything, the reverse may be true. Recent research indicates that people construe low probability events at a more abstract level than high probability events (Todorov, Goren \& Trope, 2007; Wakslak, Trope, Liberman \& Alony, 2006). Wakslak et al. (2006) suggest that this effect may be bidirectional - that behaviors construed at a low level, in terms of how they are performed rather than why, may then be seen as more likely to occur than those construed at a high level. Note that if this were true, future events would have to be construed at a more concrete level than past events in order for construal level to be responsible for the effect of timing on likelihood judgments. Because this is inconsistent both with intuition and with data indicating that people provide more detailed accounts of past than of future events (Bavelas, 1973; Weick, 1979), I believe it is unlikely that construal level can account for the tendency to see future events as more likely than equivalent past events. 


\section{Boundary Conditions}

Although I have replicated the timing effect in likelihood judgments in a number of studies, not all of my attempts to document this effect have been successful. In some investigations I have failed to obtain a past-future difference, whereas in others I have found an interaction between timing and event valence such that positive outcomes are judged to be more likely, but negative outcomes are judged to be less likely, in the future than in the past. By briefly reviewing those studies here, I hope to shed some light on the boundary conditions of this effect.

The work presented in this dissertation was initially inspired by a study by Rothbart and Snyder (1970), who found that participants betting on the outcome of a die roll expressed more confidence in their bets, and were willing to wager more money on them, if they were allowed to predict the outcome of the roll in advance than if they were asked to postdict the outcome after the die had been rolled (but before they were allowed to see the outcome). I was interested in whether their results stemmed, as they argued, from magical thinking in contexts that encourage illusory perceptions of control, or whether they could be seen as part of a broader tendency to judge any focal outcome to be more likely in the future than in the past. My attempts to replicate Rothbart and Snyder's findings using slightly different procedures have not been successful, however. In one study I asked participants to guess the outcome of a past or future coin flip, and to rate their confidence in their prediction/postdiction. In another I asked participants to roll a die and to rate, either before or after rolling the die, the likelihood of rolling a specific number (previously identified as a number that would ensure 
them either a monetary gain or a monetary loss). In a third study I asked participants either to predict or to postdict the likelihood of the experimenter drawing a specific card (which they were told would lead to either a positive or a negative outcome) from a deck of tarot cards. In none of these studies did I find a past-future difference in confidence or likelihood ratings.

Why did I fail to replicate the results obtained by Rothbart and Snyder (1970)? Although I do not know exactly why these studies failed to produce a reliable past-future difference, several possibilities are worth considering. One is that events that are just moments into the future do not seem as open and full of possibility as those that are farther away. Indeed, these events may be more likely to be incorporated into one's representation of the present than into one's representation of the future, and hence be unlikely to prompt elevated likelihood estimates. A certain amount of temporal distance between the present and the to-be-predicted event might be necessary in order to obtain a reliable timing effect.

A second possibility has to do with the fact that in each of these studies there were two main outcomes associated with the uncertain event - winning versus losing. Events for which there are only two equally salient outcomes may be unlikely to show a past-future difference, as thinking about one outcome may automatically trigger thoughts about its complement. This would lead to a perception that either event is likely to occur in the future, and hence to probability estimates closer to 50-50. The timing effect may be most likely to occur when there are many outcomes that may occur in a given time period (such as the many different activities a college student may engage in during a one-week 
period) or when the complement of the focal outcome is not as salient as the focal outcome itself, as when the two outcomes consist of an event happening or an event not happening (such as attempting suicide versus not attempting suicide).

Another possibility has to do with the role of motivation in predicting self-relevant outcomes. Recall that in Study 3, in which participants judged their own chances of experiencing a variety of events, the main effect of timing on participants' likelihood judgments was qualified by an interaction between timing and event valence. The more positive an event was, the more likely participants were to see it as more probable in the future than in the past. This is not the only study in which I observed an interaction between timing and event valence. Indeed, in another study I asked Cornell students $(n=189)$ to judge the likelihood (on a 1 to 9 scale) of either a win or a loss for the Cornell football team, either several hours before or several hours after a game in which Cornell faced off against Brown University. ${ }^{10}$ I found a significant interaction between the timing of the judgment and whether participants were asked to judge the likelihood of a win or a loss, $F(1,185)=4.37, p<.05$. Participants believed it was more likely that Cornell would win the game if they were making their judgments prior to the game than if they were doing so after the game had already occurred $(M \mathrm{~s}=5.1$ and $4.6, S D \mathrm{~s}=1.7$ and 1.9, respectively). Conversely, participants believed it less likely that Cornell would lose the game if they were making their judgments prior to the game than if they were making them after the game had occurred (Ms

\footnotetext{
${ }^{10}$ The few respondents in the past condition who knew the outcome of the game were excluded.
} 
$=5.3$ and $5.7, S D \mathrm{~s}=1.8$ and 1.8 , respectively).

I also asked participants, in a forced choice format, to predict/postdict the outcome of the game. Among participants asked to indicate which team they thought would win the game, $67 \%$ of those asked before the game selected Cornell as the winner, as compared to only $45 \%$ of those asked after the game, $\chi^{2}=4.65, p<.05$. Among participants asked to indicate which team they thought would lose the game, only $38 \%$ of those asked before the game selected Cornell as the loser, as compared to $68 \%$ of those asked after the game, $\chi^{2}=8.54, p<$ .01 . These results show a clear tendency for participants to make more optimistic judgments when predicting the future than when postdicting the past. Instead of a main effect of timing, such that participants thought that either outcome (a win or a loss for Cornell) was more likely in the future than in the past, I found an interaction between timing and outcome, such that participants thought a win was more likely but a loss was less likely in the future than in the past.

Thus, people do not invariably judge all uncertain outcomes as more likely in the future than in the past - in certain cases they judge positive events to be more likely but negative events to be less likely in the future than in the past. What does the Cornell football study have in common with Study 3? I would argue that in both cases, people were making self-relevant judgments. College students typically take a certain amount of pride in their institution's sports teams, such that a win for the school team is a win for the self and a loss for the school team is a loss for the self (Cialdini et al., 1976). Thus, the tendency for participants to make more optimistic predictions before the Cornell-Brown game than 
afterward may have resulted from the relevance of the Cornell team's success for participants' self-esteem. This conjecture is supported by the observation that the tendency for future optimism appears to be stronger among participants who reported caring quite a lot about the game, relative to those who reported caring very little about the game (although the corresponding three-way interaction between timing, outcome, and investment in the game did not quite achieve statistical significance, $\beta=$ $.435, t(181)=1.48, p=.14)$.

If people are motivated to predict that they will experience good things and avoid bad things in the future, this tendency may be at odds with the tendency to see focal events (both positive and negative) as more possible in the future than in the past. This may explain why the pastfuture asymmetry in likelihood is less reliable for self-relevant outcomes than for those that are not self-relevant, at times producing an interaction with event valence and at times producing no effect at all (i.e., when the lack of an effect for negative events weakens the overall effect of timing, resulting in a non-significant main effect). Understanding exactly when the motivation to see the future as bright and positive will trump the tendency to see it as wide open should be a focus of future research.

\section{Future Directions}

In addition to examining the role of motivation or self-relevance in moderating the past-future timing effect, future research could focus on a number of different questions. First, what role do individual differences play in this effect? I have argued that the timing effect in likelihood judgments is due to a tendency to associate the future with openness and possibility. It is likely, however, that certain groups of people do not hold 
this association to the same degree as the participants in my studies. Most of my participants were college students at an elite American university, and likely had good reason to see the future as open and full of possibility. People for whom the future is more restricted, such as those living in poverty, may be unlikely to show these effects. Similarly, older adults see the future as more limited than do younger adults (Lang \& Carstensen, 2002). Would the timing effect be reduced, or even reversed, among the elderly? Finally, if this phenomenon does indeed arise from a tendency to see the future as "open," we might expect it to be attenuated in cultures, societies, or individuals who have a more fatalistic or deterministic worldview.

A second question for future research concerns the role of focalism in producing this effect. I have argued that people assign higher likelihood estimates to uncertain future events than to equivalent past events because they see all things as more possible in the future than in the past. But why should this be the case? If all things are seen as more possible in the future, then why isn't any particular event seen as less likely? The answer lies, I believe, in the tendency for people to focus narrowly on the hypothesis at hand to the neglect of alternative possibilities. When asked to judge the likelihood that Jen will go to a party in the coming week, people think about party possibilities and fail to consider all of the other obligations Jen might have in a given week. And since the future is associated with possibility more so than the past, they see the possibility of her attending a party as greater in the coming week than in the past week. If my argument is correct, and focalism is necessary for the timing effect to occur, then defocusing people before 
they make likelihood estimates should eliminate, and perhaps even reverse, this effect. In the context of the Jen study, this could be accomplished by asking participants to first list everything that a typical college student might do in an average week. I would expect that, after being defocused in this manner, participants would judge future events to be equal in likelihood to, or perhaps even less likely than, past events. When judging a future event under normal circumstances, participants might be likely to say to themselves, "Sure, she might go to a party." But after being defocused, participants might be more likely to say to themselves, "Sure, she might go to a party, but she might be too busy studying, hanging out with friends, working a part-time job, writing papers, doing her laundry, traveling, or having friends in town." This would lead to an absence of a timing effect in likelihood judgments, or perhaps a reversal if listing events causes people to now see all of the events they listed as viable possibilities in the future (and hence each of the individual events as less likely).

A third question of interest is whether people literally see the future as "bigger" than the past. As discussed in the concluding section of Chapter Four, to the extent that the future appears more open, more positive, and more expansive than the past, it may loom larger in the mind such that people expect future events to be bigger than equivalent past events. If this were the case, we might expect people to provide greater estimates for sums or quantities if they are predicting the future than if they are postdicting the past. Moreover, as in Study 8, we might expect them to actually depict the future as bigger than the past when asked to draw future and past events. In a preliminary test of this latter hypothesis, 
I asked a sample of participants to draw a scary-looking bug that they might encounter in their kitchen late at night. Some participants were asked to imagine encountering that bug on the following weekend, whereas others were asked to imagine encountering that bug on the previous weekend. These drawings were then measured by making the smallest rectangle possible around the drawing of the bug and measuring the area of this rectangle. Participants in this study did indeed draw a larger bug if they imagined encountering it in the future than if they imagined encountering it in the past $(M \mathrm{~s}=15,603$ and 8,306 sq mm, $S D \mathrm{~s}$ $=10,774$ and 4,599 sq mm, respectively; $t(27)=2.31, \mathrm{p}=.029) .{ }^{11} \mathrm{I}$ have not been able to replicate this effect using other objects (such as an ice cream sundae or a stain on one's favorite shirt), however, so whether or not this effect is reliable remains a question for future research.

Conclusion

Psychologists have long been interested in the effects of time on judgment and behavior. Until quite recently, however, all of the research on this topic has focused on temporal distance - that is, on how perceptions and behavior are influenced by how far into the past or how far into the future an event lies. Temporal construal theory, for example, has demonstrated that distant future events are construed at a more abstract level than near future events (Trope \& Liberman, 2003). Theories of temporal discounting have examined how the value that people attach to an event varies as a function of how far into the future that event will occur (Frederick, Loewenstein \& O’Donoghue, 2002).

\footnotetext{
${ }^{11}$ Although I report the raw means and standard deviations, the data in the future condition were positively skewed and thus the significance test was conducted following a natural log transformation.
} 
And research on primacy and recency effects has shown that information is interpreted differently depending on how recently that information was encountered (Jones \& Goethals, 1987).

But very few investigations to date have examined how the temporal location (past or future) of an event influences how people interpret that event. This dissertation is an attempt to broaden the literature on the timing of events to include comparisons of past and future events. My research suggests that people associate the future with openness, possibility, and positivity more so than the past, and that this has implications for people's beliefs about the likelihood of past and future events as well as how people depict those events. Because research on this topic is still in its infancy, there are many questions yet to be answered regarding what types of judgments and behaviors are subject to a past-future asymmetry and exactly what mechanisms underlie these effects. I am confident, however, that future research will make significant advances toward answering these questions. After all, the future is wide open. 
APPENDIX

Into the Great Wide Open: Why Scholars Say the Future is Unknowable

Philosophers have long argued about the nature of time. Is the future a "great wide open," where anything can happen?

Scholars now say that the answer to that question is a resounding "yes."

"Science is a powerful tool for isolating particular causes and understanding how those causes produce their effects," said Dr. Arthur Fiske, a professor of internal medicine at Johns Hopkins University. "But science is a micro-level tool. We still can't make predictions about complex events, such as how a particular patient will respond to a treatment, how an ecosystem will be changed by the removal of a particular species, or even how some types of matter will behave in a laboratory situation."

Although they have identified some of the laws that govern physical events, scientists say, most of the operations of the universe still remain a mystery. Given the sheer number of factors that influence any given event, it is virtually impossible to say with certainty what will happen in the future.

"Although it's theoretically possible to have complete knowledge of physical matter and the laws governing that matter at any one time, in reality we don't have this kind of knowledge," said Dr. Robert DiPietro, professor of chemistry at Harvard University. "So we just can't know what the future holds." 
These claims are bolstered by recent advances in quantum theory, which casts doubt on the possibility that scientists can ever have complete knowledge of the workings of the universe.

In classical physics, it was believed that if one knew the initial state of a system with infinite precision, one could predict the behavior of the system infinitely far into the future. According to the modern theory of quantum mechanics, however, there is a fundamental limit on the ability to make such predictions, because of the inability to collect the initial data with unlimited precision.

"Quantum mechanics provides probabilistic results because the physical universe is itself probabilistic rather than deterministic," said Dr. Anne Cho, professor of theoretical physics at California Institute of Technology. "In essence, many different worlds are possible, and we don't know until the moment arrives which possible world we will experience."

Findings such as these have implications for a number of academic disciplines, most notably philosophy. Indeed, philosophers are now looking to the sciences to help revise theories of time and space.

"Research in the hard sciences in now supporting the argument many philosophers have made for centuries, that the future is indeterminate," said Alan Koutsioroumbus, professor of philosophy at Swarthmore College. "It cannot be predicted before it occurs, and in this way, the future is wide open." 
A Closed Book: Why Scholars Say the Future is Predetermined

Philosophers have long argued about the nature of time. Is the future predetermined by the events of the past and present, like a novel whose ending, although unknown to the reader, is already written?

Scholars now say that the answer to that question is a resounding "yes."

"Science is a powerful tool for isolating particular causes and understanding how those causes produce their effects," said Dr. Arthur Fiske, a professor of internal medicine at Johns Hopkins University. "Using science, we have learned that all events are causally determined by the events that precede them. In this way, the future is already fixed by the events of the past and present."

Although the sheer number of factors that influence any given event makes it difficult in everyday life to predict what will happen next, scientists say, if it were possible to measure every one of these factors scientists could compute the time and place of every event that will ever occur.

"Once the initial conditions of the universe have been established the rest of the history of the universe follows inevitably," said Dr. Robert DiPietro, professor of chemistry at Harvard University. "In this sense, the basic particles of the universe operate in the same fashion as the rolling balls on a billiard table, moving and striking each other in predictable ways to produce predictable results."

These claims are bolstered by recent advances in chaos theory, which, despite its misleading name, posits that the universe is deterministic and that events that look random on the surface can be 
traced back to prior, eliciting condition. The most well-known example of the theory, the "butterfly effect," illustrates how a seemingly inconsequential event, such as the flapping of a butterfly's wings in Brazil, can initiate a chain of events that results in serious consequences, such as a tornado in Texas.

"Chaos theory can predict the behavior of a variety of complex systems, including the weather, plate tectonics, the solar system, economics, and population growth, just to name a few," said Dr. Anne Cho, professor of theoretical physics at California Institute of Technology. "Even these seemingly chaotic events are the products of a very orderly, fully deterministic universe."

Findings such as these have implications for a number of academic disciplines, most notably philosophy. Indeed, philosophers are now looking to the sciences to help revise theories of time and space.

"Research in the hard sciences in now supporting the argument many philosophers have made for centuries, that the future is predetermined," said Alan Koutsioroumbus, professor of philosophy at Swarthmore College. "Every event is perfectly predictable from the events that proceeded it, so even if we don't yet know the ending, the future is a closed book." 


\section{REFERENCES}

Bargh, J. A., \& Chartrand, T. L. (2000). The mind in the middle: A practical guide to priming and automaticity research. In H. T. Reis \& C. M. Judd (Eds.), Handbook of research methods in social and personality psychology (pp. 253-285). New York: Cambridge University Press.

Bavelas, J. B. (1973). Effects of the temporal context of information. Psychological Reports, 32, 695-698.

Brun, W., \& Teigen, K. H. (1990). Prediction and postdiction preferences in guessing. Journal of Behavioral Decision Making, 3, 17-28.

Buehler, R., Griffin, D. W., \& Ross, M. (1994). Exploring the planning fallacy: Why people underestimate their task completion times. Journal of Personality and Social Psychology, 67, 366-381.

Caruso, E. M., Gilbert, D. T., \& Wilson, T. D. (2007). A wrinkle in time: Asymmetric valuation of past and future events. Manuscript under review.

Cialdini, R. B., Borden, R. J., Thorne, A., Walker, M. R., Freeman, S., \& Sloan, L. R. (1976). Basking in reflected glory: Three (football) field studies. Journal of Personality and Social Psychology, 34, 366-375.

Dasgupta, N., \& Greenwald, A. G. (2001). On the malleability of automatic attitudes: Combating automatic prejudice with images of admired and disliked individuals. Journal of Personality and Social Psychology, 81, 800-814. 
Epley, N., \& Dunning, D. (2000). Feeling "holier than thou": Are selfserving assessments produced by errors in self or social prediction? Journal of Personality and Social Psychology, 79, 861-875.

Fabrigar, L. R., \& Krosnick, J. A. (1995). Attitude importance and the false consensus effect. Personality and Social Psychology Bulletin, 21, 468-49.

Fischhoff, B. (1975). Hindsight does not equal foresight: The effect of outcome knowledge on judgment under uncertainty. Journal of Experimental Psychology: Human perception and performance, 1, 288-299.

Fox, C. R., \& Tversky, A. (1995). Ambiguity aversion and comparative ignorance. The Quarterly Journal of Economics, 110, 585-603.

Frederick, S., Loewenstein, G., and O’Donoghue, T. (2002). Time discounting and time preference: A critical review. Journal of Economic Literature, 40, 351-401.

Grant, S. J., \& Tybout, A. M. (2007). The effects of temporal frame on new product evaluation: The role of uncertainty. Manuscript under revision.

Greenwald, A. G., \& Farnham, S. D. (2000). Using the Implicit Association Test to measure self-esteem and self-concept. Journal of Personality and Social Psychology, 79, 1022-1038.

Greenwald, A. G., McGhee, D. E., \& Schwartz, J. K. L. (1998).

Measuring individual differences in implicit cognition: The Implicit Association Test. Journal of Personality and Social Psychology, 74, 1464-1480.

Greenwald, A. G., Nosek, B. A., \& Banaji, M. R. (2003). Understanding 
and using the Implicit Association Test: I. An improved scoring algorithm. Journal of Personality and Social Psychology, 85, $197-$ 216.

Jones, E. E., \& Goethals, G. R. (1987). Order effects in impression formation: Attribution context and the nature of the entity. In E. E. Jones, D. E. Kanouse, H. H. Kelley, R. E. Nisbett, S. Valins, \& B. Weiner (Eds.), Attribution: Perceiving the causes of behavior (pp. 27-46). Hillsdale, NJ: Erlbaum.

Kahneman, D., \& Tverksy, A. (1973). On the psychology of prediction. Psychological Review, 80, 237-251.

Kane, J., Van Boven, L., \& McGraw, A. P. (2007, January). Take it from the top (or bottom): Temporal perspective and bottom-up versus top-down processing. In K. C. Hanko and E. F. Williams (Chairs), Judgment in the context of time: How thinking about the future differs from thinking about the past. Symposium conducted at the meeting of the Society for Personality and Social Psychology, Memphis, TN.

Klayman, J., \& Ha, Y. (1987). Confirmation, disconfirmation, and information in hypothesis testing. Psychological Review, 94, 211228.

Lang, F. R., \& Carstensen, L. L. (2002). Time counts: Future time perspective, goals, and social relationships. Psychology and Aging, $17,125-139$.

Maison, D., Greenwald, A. G., \& Bruin, R. (2001). The Implicit Association Test as a measure of implicit consumer attitudes. Polish Psychological Bulletin, 2, 61-79. 
Morris, M. W., Sim, G. L. H., \& Girotto, V. (1998). Distinguishing sources of cooperation in the one-round prisoner's dilemma: Evidence for cooperative decisions based on the illusion of control. Journal of Experimental Social Psychology, 34, 494-512.

Mullen, B., Atkins, J. L., Champion, D. S., Edwards, C., Hardy, D., Story, J. E., et al. (1985). The false consensus effect: A meta-analysis of 115 hypothesis tests. Journal of Experimental Social Psychology, $21,262-283$.

Newby-Clark, I. R., \& Ross, M. (2003). Conceiving the past and future. Personality and Social Psychology Bulletin, 29, 807-818.

Robinson, E. J., Rowley, M. G., Beck, S. R., Carroll, D. J., \& Apperly, I. A. (2006). Children's sensitivity to their own relative ignorance: Handling of possibilities under epistemic and physical uncertainty. Child Development, 77, 1642-1655.

Ross, L., Greene, D., \& House, P. (1977). The false consensus effect: An egocentric bias in social perception and attribution processes. Journal of Experimental Social Psychology, 13, 279-301.

Rothbart, M., \& Snyder, M. (1970). Confidence in the prediction and postdiction of an uncertain outcome. Canadian Journal of Behavioral Science, 2, 38-43.

Sanna, L. J., \& Swim, J. K. (1992). Temporal perspective and attributions: The role of causal stability and certainty. Basic and Applied Social Psychology, 13, 371-387.

Snyder, M., \& Swann, W. B. (1978). Hypothesis-testing processes in social interaction. Journal of Personality and Social Psychology, $36,1202-1212$. 
Strickland, L. H., Lewicki, R. J., \& Katz, A. M. (1966). Temporal orientation and perceived control as determinants of risk-taking. Journal of Experimental Social Psychology, 2, 143-151.

Tetlock, P. E. (1992). The impact of accountability on judgment and choice: Toward a social contingency model. In M. Zanna (Ed.), Advances in experimental social psychology (Vol. 25) (pp. 331376). New York: Academic Press.

Todorov, A., Goren, A., \& Trope, Y. (2007). Probability as psychological distance: Construal and preferences. Journal of Experimental Social Psychology, 43, 473-482.

Trope, Y., \& Liberman, N. (2003). Temporal construal. Psychological Review, 110, 403-421.

Van Boven, L., \& Ashworth, L. (2007). Looking forward, looking back: Anticipation is more evocative than retrospection. Journal of Experimental Psychology: General, 136, 289-300.

Vosgerau, J., Wertenbroch, K., \& Carmon, Z. (2006). Indeterminacy and live television. Journal of Consumer Research, 32, 487-495.

Wakslak, C. J., Trope, Y., Liberman, N., \& Alony, R. (2006). Seeing the forest when entry is unlikely: Probability and the mental representation of events. Journal of Experimental Psychology: General, 135, 641-653.

Weick, K. E. (1979). The Social Psychology of Organizations. Reading, MA: Addison-Wesley.

Weinstein, N. D. (1980). Unrealistic optimism about future life events. Journal of Personality and Social Psychology, 39, 806-820. 
Wilson, T. D., Wheatley, T. P., Meyers, J. M., Gilbert, D. T., \& Axsom, D. (2000). Focalism: A source of durability bias in affective forecasting. Journal of Personality and Social Psychology, 78, 821836. 